\title{
Preparation, Raman Spectroscopy, Surface Morphology and Optical Properties of TiPcCl2 Nanostructured Films: Thickness Effect
}

Taymour Hamdalla ( $\square$ taymour_76@yahoo.com )

University of Tabuk https://orcid.org/0000-0002-0807-7956

A.A.A. Darwish

University of Tabuk

S.A. Al-Ghamdi

University of Tabuk

Ahmed Obaid M. Alzahrani

King Abdulaziz University

E.F.M. El-Zaidia

University of Tabuk

Nasser A. Alamrani

Tabuk university

Mohamed A. Elblbesy

tabuk university

\section{I.S. Yahia}

king Khaled university

\section{Research Article}

Keywords: Organic films, nanostructure, optical properties, dielectric constants, nonlinear optical

Posted Date: February 9th, 2021

DOI: https://doi.org/10.21203/rs.3.rs-175277/v1

License: (1) (1) This work is licensed under a Creative Commons Attribution 4.0 International License.

Read Full License

Version of Record: A version of this preprint was published at Optical and Quantum Electronics on August 14th, 2021. See the published version at https://doi.org/10.1007/s11082-021-03163-9. 


\title{
Preparation, Raman spectroscopy, surface morphology and optical properties of $\mathrm{TiPcCl}_{2}$ nanostructured films: thickness effect
}

\author{
Taymour A. Hamdalla ${ }^{1,2, *}$, A.A.A. Darwish ${ }^{1,3}$, S.A. Al-Ghamdi ${ }^{4}$,Ahmed Obaid M. Alzahrani ${ }^{5,6}$, \\ E.F.M. El-Zaidia ${ }^{4,7}$, Nasser A. Alamrani ${ }^{8}$, Mohamed A. Elblbesy ${ }^{9,10}$ and I.S. Yahia ${ }^{11,12}$ \\ 1) Department of Physics and Nanotechnology Research Unit, Faculty of Science, University of Tabuk, Tabuk 71491, Saudi \\ Arabia \\ 2) Department of Physics, Faculty of Science, Alexandria University, Alexandria, Egypt \\ 3) Department of Physics, Faculty of Education at Al-Mahweet, Sana'a University, Al-Mahweet, Yemen. \\ 4) Department of Physics, Faculty of Science, University of Tabuk, Tabuk 71491, Saudi Arabia \\ 5) Center of Nanotechnology, King Abdulaziz University, Jeddah, Saudi Arabia \\ 6) Physics Department, Faculty of Science, King Abdulaziz, University, Jeddah, Saudi Arabia \\ 7) Department of Physics, Faculty of Education, Ain Shams University, Roxy 11757, Cairo, Egypt. \\ 8) Department of Chemistry, Faculty of Science, University of Tabuk, Tabuk 71491, Saudi Arabia \\ 9) Department of Medical Laboratory Technology, Faculty of Applied Medical Sciences, University of Tabuk, Tabuk 71491, \\ Saudi Arabia. \\ 10) Department of Medical Biophysics, Medical Research Institute, Alexandria University, Alexandria 21561, Egypt \\ 11) Research Center for Advanced Materials Science (RCAMS), King Khalid University, and Advanced Functional Materials \\ \& Optoelectronic Laboratory (AFMOL), Department of Physics, Faculty of Science, King Khalid University, P.O. Box \\ 9004, Abha, Saudi Arabia. \\ 12) Nanoscience Laboratory for Environmental and Biomedical Applications (NLEBA), Semiconductor Lab., Department of \\ Physics, Faculty of Education, Ain Shams University, Roxy 11757, Cairo, Egypt.
}

\begin{abstract}
Phthalocyanines are of a broad interest in photovoltaic applications. In this study, films of titanium-phthalocyanine-chloride $\left(\mathrm{TiPcCl}_{2}\right)$ were prepared by the thermal evaporation method. The molecular structure was studied by Raman spectrometer, showing a match between the spectra of the powder and the prepared films. The films' surface was examined by the atomic force microscope, revealing grain size and surface roughness of $\mathrm{TiPcCl}_{2}$ thin films to be 223 and $41 \mathrm{~nm}$, respectively, for a $100 \mathrm{~nm}$ thickness. The energy gap was determined to be $1.5 \mathrm{eV}$, with no observable effect by the thickness change. Additionally, the linear and nonlinear optical constants were calculated from reflectance and transmittance measurements. The values of third nonlinear susceptibility are in order of $10^{-12} \mathrm{esu}$, which is compatible with other phthalocyanines. The nonlinear optical constants indicate that $\mathrm{TiPcCl}_{2}$ films could also be used for optical laser limiters.
\end{abstract}

Keywords: Organic films; nanostructure; optical properties; dielectric constants, nonlinear optical

\footnotetext{
*Corresponding author: Taymour A. Hamdalla

E-mail address: taymour_76@yahoo.com
} 


\section{Introduction}

Phthalocyanine $(\mathrm{Pc})$ dyes are photosensitizers in the near IR region with unique photochemical, electrochemical, and thermal properties [1]. Pc is an aromatic dye with different colors determined by the substitution of the benzene rings. Pc is widely used in various scientific fields such as optical communication, electronic, optoelectronic, and solar cell [2,3]. Pc properties are attractive due to long-range periodic order, free of grain boundaries, and minimal traps and defects [4].

Pc chemical structure comprises varying numbers of single and multiple bonds, so molecules exist in high-grade electronically excited states [5]._Several metals, such as $\mathrm{Zn}, \mathrm{Pb}, \mathrm{Cu}, \mathrm{Ga}$, etc., are integrated into Pc's side group to improve its structural and desirable properties. Different studies have shown that Pc's optical properties and applications are influenced by central metal nature [6-8]. Metal phthalocyanine (MPc) days have significant linear and nonlinear optical properties that can be employed in optical sensors, optical elements, and protect human eyes from highintensity lasers [9].

There have been very few studies of halogenated MPc, mainly limited to indicating that they have ideal properties for gas sensing applications [10]. The films of $\mathrm{AlPcCl}[11]$ and $\mathrm{GaPcCl}[12$, 13] were analyzed to investigate their optical properties. These films exhibit indirectly allowed transitions, and different dispersion and absorption parameters were calculated. In addition, the electrical measurement of $\mathrm{AlPcCl}$ was performed to determine the energy gap by cyclic voltammetry and was found to be $1.42 \mathrm{eV}$ [14]. Rajesh and Menon have examined the electrical conductivity of $\mathrm{MnPcCl}$ films [15]. It has been found that the impact of oxygen on electrical parameters was significant. As a high-performance limiter, Darwish et al. [16] studied the highly branched synthesis parameters in (III)Pc polymer. The investigation of the characterization of the lifetime of $\mathrm{GaPcCl}$ was carried out by Chauke et al. [17]

One of the halogenated MPc is Titanium-phthalocyanine-dichloride $\left(\mathrm{TiPcCl}_{2}\right)$, where $\mathrm{Ti}^{+4}$ has many more advantageous properties than other metals, which have high corrosion resistance and a high strength-to-density ratio [18]. Cherian and Menon presented a study of $\mathrm{TiPcCl}_{2}$ films prepared by thermal evaporation [19]. The thermal activation energy of the electrical conduction is affected by annealing and the presence of oxygen. Nevertheless, the energy gap was not affected 
by annealing [19]. Titanium-phthalocyanine-dichloride $\left(\mathrm{TiPcCl}_{2}\right)$ compound has not received extensive research and study, although it is essential for optoelectronic applications.

The study of film thickness's influence on optical properties and film morphology gives us a detailed insight into many new conditions that have taken place during the material deposition in substrates. The alteration of bandgap with a change in the film thickness can be a useful tool for examining how oxide layers can be produced within the film structure. The present work is focused on studying the influence of film thickness on characterization, linear, and nonlinear optical properties of $\mathrm{TiPcCl}_{2}$ thin films.

\section{Experimental techniques}

$\mathrm{TiPcCl}_{2}$ powder was purchased from Sigma-Aldrich Company. The molecular structure of $\mathrm{TiPcCl}_{2}$ has been introduced in Scheme 1. The subsequent $\mathrm{TiPcCl}_{2}$ films were then deposited with different thicknesses of 100, 170, 270, and $377 \mathrm{~nm}$ onto a highly cleaned glass utilizing the vacuum coating system (HHV Auto 306) at the pressure of $2.5 \times 10^{-4} \mathrm{~Pa}$. We used a quartz monitor to control the thin-film thickness, and the deposition rate was at $1.5 \mathrm{~nm} / \mathrm{s}$. The interferometric process was applied to determine the exact thickness of the $\mathrm{TiPcCl}_{2}$ film [20].

The vibrational properties of $\mathrm{TiPcCl}_{2}$ films have been recorded by Raman spectroscopy using a Dilor XY modular spectrometer. The morphology of $\mathrm{TiPcCl}_{2}$ films with different thicknesses was investigated utilizing an Atomic Force Microscope (AFM) mode NT-MDT-Type

Next, Russia. Optical spectroscopic characterization was studied by a double-beam spectrophotometer (JASCO, V-570), which was utilized to record the spectra of transmittance, $T$, and reflectance, $R$, in the wavelength range between $200-2500 \mathrm{~nm}$ for the $\mathrm{TiPcCl}_{2}$ films. Then, $T$ and $R$ were used to calculate the optical constants [21, 22].

\section{Results and discussion}

\subsection{Raman spectroscopy}

Raman spectroscopy is used to investigate the molecular structure of the $\mathrm{TiPcCl}_{2}$ films, such as group structure, functional groups, and structural parameter changes with the change of film thickness. The experimental data of Raman spectra of $\mathrm{TiPcCl}_{2}$ thin films for $\mathrm{TiPcCl}_{2}$ powder 
sample and films of the thickness of 100, 170, 270, and $377 \mathrm{~nm}$ are shown in Fig. 1 (a-e). The most intense vibrational peaks of the Raman spectrum of $\mathrm{TiPcCl}_{2}$ thin films are listed in Table 1. This figure shows that the Raman spectra of the deposited films are like the powder spectra and do not alter with evaporation, suggesting that the thermal evaporation approach is an excellent way to obtain non-dissociated $\mathrm{TiPcCl}_{2}$ films. However, the phthalocyanine ring's characteristic vibration absorption peaks were assigned to 596 and $1337 \mathrm{~cm}^{-1}$ [23]. The peaks related to the $\mathrm{C}=\mathrm{C}$ bond existed at the wavenumber of 1612 and $1519 \mathrm{~cm}^{-1}$. At wavenumber $1430 \mathrm{~cm}^{-1}$, a high peak related to $\mathrm{C}-\mathrm{C}$ bonds appears within our fabricated materials. At wavenumber corresponding to $681 \mathrm{~cm}^{-1}$, the presence of $\mathrm{C}-\mathrm{O}$ bonds appears to be strong. The Raman spectra of $\mathrm{TiPcCl}_{2}$ are close to other MPc with different central metals [23].

\subsection{Morphological studies}

AFM is utilized for examining the surface of organic thin films, and it was used in this study to calculate the grain size and the roughness. Fig. 2 showed $2 \mathrm{D}$ grain size patterns of $\mathrm{TiPcCl}_{2}$ thin films with various thicknesses. $\mathrm{TiPcCl}_{2}$ thin films show a uniformly nano spherical particle. The values of grains size for $\mathrm{TiPcCl}_{2}$ thin films at different thicknesses are listed in Table 1. It can be observed that the grain size increased with increasing the film thickness. Also, an increase in grain size may be due to an improvement in crystallinity and an increase in clusters' development, contributing to small grain agglomeration [24]. Such agglomerated grains merge to create larger grains with better crystallinity. The grain size and roughness surface for $\mathrm{TiPcCl}_{2}$ thin films were measured and found to be 223 and $41 \mathrm{~nm}$, respectively, for a thickness of $100 \mathrm{~nm}$. TiPcCl 2 films have a larger grain size and a lower surface roughness than those reported for $\mathrm{GaPcCl}$ [12]. In thin films, the composition of the surfaces significantly affects the transport of conduction electrons. In the case of mesoscopic roughness in the range of a few nanometers, this because of the film's varying thickness, which results in a spatially variable conductivity. Also, microscopic roughness can lead to electrons' dispersion and further improves the thin film's resistance [25].

\subsection{Optical and dielectric constants}

The optical transmittance and reflectance of the thin films of $\mathrm{TiPcCl}_{2}$ with a thickness of 100, 170, 270, and $377 \mathrm{~nm}$ have been illustrated in Fig. 3. This figure shows the homogeneity of 
$\mathrm{TiPcCl}_{2}$ thin films. It can be noted from Fig. 3, at wavelengths $(\lambda)$ greater than $960 \mathrm{~nm}$, that the transmission increases steadily until it reaches approximately $96 \%$. The light transmission within $\mathrm{TiPcCl}_{2}$ thin films was affected by the thickness, as shown in Fig. 3. Therefore, we can conclude that the absorption of light within $\mathrm{TiPcCl}_{2}$ films augments with increasing material thickness. The decrease in the transmission is due to the grain size change, where a larger grain size acts to increase the absorption of the fabricated material [26]. On the other hand, $\mathrm{TiPcCl}_{2}$ thin films' reflectance spectra are distinguished by specific peaks for $\lambda<1000 \mathrm{~nm}$ in the region associated with the electronic transitions in $\mathrm{TiPcCl}_{2}$ thin films. At $\lambda>1400 \mathrm{~nm}$, the film's reflectance decreases with an increase in wavelength and increases with increasing the film thickness. In this wavelength range, the $\mathrm{TiPcCl}_{2}$ thin films become transparent for light, where the sum of $T$ and $R$ is approximately equal to unity.

A deep understanding of optical constants is a valuable method to learn the photonic and optoelectronic behavior [27]. The complex refractive index, $n^{*}$, is given by [28]:

$n^{*}=n+\mathrm{i} k$

where $n$ is the real part and called the refractive index while $k$ is the imaginary part and called the extinction coefficient. These parameters were calculated as [21, 22]:

$\alpha=\frac{1}{d} \ln \left(\frac{1-R^{2}}{2 T}+\sqrt{R^{2}+\frac{1-R^{2}}{4 T^{2}}}\right)$

$k=\alpha \lambda / 4 \pi$

$n=\frac{1+R}{1-R}+\sqrt{\frac{4 R}{(R-1)^{2}}-k^{2}}$

where $\alpha$ : the absorption coefficient, and $d$ : the thickness of $\mathrm{TiPcCl}_{2}$ film.

The variation of refractive index, $n$, with the wavelength for $\mathrm{TiPcCl}_{2}$ thin film at various thicknesses are shown in Fig. 4a. There are different high energy peaks at $\lambda<1000 \mathrm{~nm}$, which exhibit a multi-oscillator behavior. At $\lambda>1000 \mathrm{~nm}$, the refractive index decreases by about $19 \%$ as the wavelength increases, indicating dispersion increase in this wavelength range. Further, the values of $n$ increase with increasing the thickness, which could be explained by the film's discontinuity formed during the deposition's initial stages [29]. The extinction index, $k$, of different $\mathrm{TiPcCl}_{2}$ thin film thicknesses as a function of the wavelength is introduced in Fig. 4b. Three peaks in the absorption curve have been found at 225, 350, and $715 \mathrm{~nm}$. These peaks are like the 
phthalocyanine compounds [30], as they show three absorption regions, which are the C-band at $225 \mathrm{~nm}$, the B-band at $350 \mathrm{~nm}$, and the last area is the Q-band at $715 \mathrm{~nm}$.

The design of highly efficient optoelectronic devices depends on the complex dielectric constant $\left(\varepsilon^{*}=\varepsilon_{1}+\mathrm{i} \varepsilon_{2}\right)$ as a significant quantity, due to the knowledge associated with the dielectric constant that it offers a relaxed view of the interactions between photons and electrons in a material [31]. The optical and electrical properties of the materials are related using the dielectric properties. The dielectric constant, $\varepsilon_{1}$, and dielectric loss, $\varepsilon_{2}$, of $\mathrm{TiPcCl}_{2}$ could be calculated, respectively as $[32,33]$ :

$\varepsilon_{1}=n^{2}-k^{2}$

$\varepsilon_{2}=2 n k$

Fig. 5 shows the spectral distribution of $\varepsilon_{1}$ and $\varepsilon_{2}$ with hv. There is a remarkably different behavior that has appeared in the figures of both $\varepsilon_{1}$ and $\varepsilon_{2}$. This conduct may be attributed to the different interactions in the center of electrons in $\mathrm{TiPcCl}_{2}$ film and the incident photons that cause a difference in the spectrum shapes of $\varepsilon_{1}$ and $\varepsilon_{2}$ [34]. Two dielectric maximums that inferred the possibility of dielectric applications of $\mathrm{TiPcCl}_{2}$ films could also be observed. According to Zhang et al. [35], the maximums released within the energy range of 1.5-2.2 eV, as shown in Fig. 5, indicate an energy storage area where energy can be stored. This shines a spotlight on the application of $\mathrm{TiPcCl}_{2}$ films for energy storage.

\subsection{Absorption and dispersion analysis}

The absorption of light from organic materials provides a great insight into the knowledge of the transfer of electrons between energy levels. Fig. 6 depicts the absorption coefficient of $\mathrm{TiPcCl}_{2}$ thin film spectra against the photon energy in the Q, B, and $\mathrm{C}$ bands. In the three-band, the wavelength affects the absorption coefficient. The absorption coefficient decreased at the Cband due to the band absorption generated by direct Coulomb encounters with lattice constituents [36]. The increased material thickness causes a reduction in inter-atomic spacing within our synthesized thin film, and this affects the material absorption [36].

However, the Q-band consists of a $1.74 \mathrm{eV}$ peak and a $1.87 \mathrm{eV}$ shoulder. The peak of the Q-band was allocated to the first $\pi-\pi^{*}$ transition of the phthalocyanine macrocycle [37]. The Q- 
band's shoulder was explained differently, as a second $\pi-\pi^{*}$ transition, as an excitation peak [37] as an internal vibrational interval, and as a surface state. In the high-energy region of the Soret band around 3.58 and $4.24 \mathrm{eV}$, the critical indicator of the large variations in the phthalocyanine absorption spectrum in that area suggests the existence of a d-band correlating with the central metal atom [37]. In the high energy region (5.59 eV), the absorption of $\mathrm{TiPcCl}_{2}$ appears a band known as C-band like other MPc, which is attributed to the $\pi$-d transitions [37].

Researchers study the absorption edge for phthalocyanine and its derivatives thin film to provide information on inner band transitions [11-13, 19]. The electronic transitions in organic materials occur mainly between the highest occupied molecular (HOMO) and the lowest molecular orbital (LUMO). The area between them is the band gap, and Tauc's relation can detect the optical band gap [38]:

$$
(\alpha h v)^{L}=H\left(h v-E_{g}\right)
$$

where $H$ is a constant, $h v$ is photon energy, and $E_{g}$ is the energy band gap. The constant $L$ depends on the transition type and takes the value $1 / 2$ and 2 for an indirect transition and a direct transition, respectively. Fig. 7 shows the relation between $(\alpha h v)^{1 / 2}$ and photon energy for $\mathrm{TiPcCl}_{2}$ thin films at various thicknesses, and two energy bands are described in this figure. These band energies describe the lowest values as the optical band gap energy $\left(E_{g 1}\right)$, which is a consequence of several factors, including dislocations and vacancies, within the microstructure film [39]. The higher band gap energy is called the fundamental band energy gap $\left(E_{g 2}\right)$ and the transition from $\pi$ to $\pi^{*}$ generally explains this [39]. The band gap energies values for various $\mathrm{TiPcCl}_{2}$ films are not affecting by the thickness of the film. which confirms the thermal vacuum evaporation competence to prevent oxidation layers from occurring during the creation of the $\mathrm{TiPcCl}_{2}$ deposited materials. The average energy gap, $E_{g 1}$, is $1.5 \mathrm{eV}$, whereas the average $E_{g 2}$ is $2.95 \mathrm{eV}$. The comparison with other related compounds of phthalocyanine $[11,12,40]$ of band gap energy value was shown in Table 2.

With the magnitudes of the refractive index, several main linear optical parameters can be calculated. These parameters are the single oscillator energy $\left(E_{s}\right)$, the dispersion energy $\left(E_{d}\right)$, highfrequency dielectric constant $\left(\varepsilon_{\infty}\right)$, the carrier concentration $(N)$, and the lattice dielectric constant $\left(\varepsilon_{L}\right)$, and they increase the understanding of the optical properties of $\mathrm{TiPcCl}_{2}$ films. For example, 
$E_{s}$ symbolizes the single oscillator energy influenced by excitons' formation through the material. At the same time, $E_{d}$ is used primarily to evaluate the optical interband transitions [40]. The refractive index is analyzed using the following equations [41, 42]:

$n^{2}-1=\frac{E_{d} E_{S}}{E_{S}^{2}-(h v)^{2}}$

$n^{2}=\varepsilon_{L}-\frac{e^{2} N}{4 \pi \varepsilon_{o} m^{*} c^{2}} \lambda^{2}$

where $\varepsilon_{o}:$ the free space dielectric constant, $m^{*}$ : the electron effective mass, and $e$ : the electron's charge. Fig. 8a shows the change of $\left(n^{2}-1\right)^{-1}$ with $(h v)^{2}$, while Fig. $8 \mathrm{~b}$ shows the evolution of $n^{2}$ with $\lambda^{2}$. All the optical parameters are listed in Table 2. The increase of these optical parameters with increasing film thickness could be interpreted by the variation in ionization, which occurs primarily due to the rise in the number of cations in coordination with nearby anions [43]. Table 2 has also reported similarities with the relative compounds of phthalocyanine of these constants.

\subsection{Calculated nonlinear optical constants}

Studying the nonlinear optical properties of organic dyes is vital for different fields of science, such as optical fiber cables, optical gadgets modulators [44]. In nano-photonics science, the nonlinear optical materials also play a critical turn. The organically replaced molecules together demonstrate observable non-linear optics and electrooptical impact. These materials may be used for doubling or tripling the frequency of laser light. They are also desirable for high-speed data processing and essential to many emerging technologies, including digital and optical computing [45].

Nonlinear optical properties are primarily understood by the study of third nonlinear susceptibility $\left(\chi^{(3)}\right)$ and nonlinear refractive index $\left(n_{2}\right)$. From Miller's generalized law [46], the $\chi^{(3)}$ and $n_{2}$ values for $h v \rightarrow 0$ can be evaluated as follows:

$\chi^{(3)}=1.7 \times 10^{-10}\left(\frac{n_{0}^{2}-1}{4 \pi}\right)^{4}$

$n_{2}=\frac{12 \pi \chi^{(3)}}{n_{0}}$

where $n_{o}$ : the linear refractive index at $h v \rightarrow 0$. Fig. 9 presents the variance of $n_{o}, \chi^{(3),}$ and $n_{2}$ as a function of the film's thickness. As shown in this figure, the values of $n_{o}, \chi^{(3)}$ and $n_{2}$ indicate an 
increase in the thickness of $\mathrm{TiPcCl}_{2}$ thin film. The increase in the values of the three parameters with the increase in the thickness could be related to the change of the delocalization degree of $\pi$ electron and the aligned chains in the direction of the induced electric field [47]. Also, the values of $\chi^{(3)}$ are $10^{-12} \mathrm{esu}$, which is compatible with other phthalocyanines [11-13]. The obtained results of $\chi^{(3)}$ and $n_{2}$ indicate that $\mathrm{TiPcCl}_{2}$ films are excellent nonlinear optical materials, mainly if used as optical limiters.

\section{Conclusions}

In this paper, the morphology and the optical properties of $\mathrm{TiPcCl}_{2}$ thin film with different thicknesses have been studied. These films were prepared in the usual manner by thermal evaporation. The molecular structure was analyzed by a Raman spectrometer. The films' surface morphology was examined by atomic force microscope, and then the linear and nonlinear optical properties were studied. From this study, we conclude the following:

- The molecular structure of the prepared films is identical to the powder, and this indicates that homogeneous films can be obtained from the $\mathrm{TiPcCl}_{2}$ compound by the thermal evaporation method.

- The morphology studied showed that $\mathrm{TiPcCl}_{2}$ thin film has an average grain size and roughness of 223 and $41 \mathrm{~nm}$, respectively.

- The dielectric constants inferred the possibility of dielectric applications of $\mathrm{TiPcCl}_{2}$ films could also be observed. They also showed maximums released within the energy range of 1.5-2.2 eV, indicating an energy storage area. This shines a spotlight on the application of $\mathrm{TiPcCl}_{2}$ films for energy storage.

- The band gap energy values for different TiPcCl2 thin films are not affected by the film's thickness. The average energy gap is $1.5 \mathrm{eV}$, which makes these films attractive for photovoltaic applications. 
- Nonlinear third susceptibility values are $10^{-12} \mathrm{esu}$, which is compatible with other phthalocyanines. The obtained results of nonlinear optical parameters indicate that $\mathrm{TiPcCl}_{2}$ films are excellent nonlinear optical materials, mainly if used as optical limiters.

\section{Acknowledgment}

The authors extend their appreciation to the Deanship of Scientific Research at University of Tabuk for funding this work through Research Group RGP-S-1441-008.

\section{Conflict of Interest:}

The authors declare that there is no conflict of interest regarding the publication of this paper. 


\section{References}

[1] Z. Odabaş, E.B. Orman, M. Durmuş, F. Dumludağ, A.R. Özkaya, M. Buluta, Novel alpha-7oxy-4-(4-methoxyphenyl)-8-methylcoumarin substituted metal-free, $\mathrm{Co}$ (II) and $\mathrm{Zn}$ (II) phthalocyanines: Photochemistry, photophysics, conductance and electrochemistry, Dyes and Pigments 95 (2012) 540-552

[2] Y. Zhang, J.F. Lovell, Recent applications of phthalocyanines and naphthalocyanines for imaging and therapy. Wiley Interdisciplinary Reviews: Nanomedicine and Nanobiotechnology, 2017. 9(1): p. e1420 doi:10.1002/wnan.1420

[3] T.V. Basova, V.G. Kiselev, F. Latteyer, H. Peisert, T. Chasséd, Molecular organization in the thin films of gallium(III) phthalocyanine chloride and its $\mu$-(oxo)dimer: Optical spectroscopy and XPS study, Applied Surface Science 322 (2014) 242-248

[4] C. Wang, H. Dong, L. Jiang, and W. Hu, Organic semiconductor crystals, Chemical Society Reviews, 47 (2018) 422-500.

[5] W.M. Darwish, A.M. Darwish, and E.A. Al-Ashkar, Indium (III) phthalocyanine ekaconjugated polymer as high-performance optical limiter upon nanosecond laser irradiation. High Performance Polymers, 2016. 28(6): p. 651-659.

[6] J. Wang, W. Dong, Bo Gao, D. Liu, Q. Duan, Syntheses and characterizations of Zn (II) Phthalocyanines\& Naphthopyrans based polymers for improved nonlinear optical properties, Dyes and Pigments 182 (2020) 108662

[7] V. Viswanath, G. Subodh, C.I. Muneera, Zinc Phthalocyanine-Poly (Vinyl Alcohol) nanocomposite films: Low threshold optical limiting properties based on third-order nonlinear absorption response, Optics and Laser Technology 127 (2020) 106168.

[8] N. Kaur, A. Mahajan, D.P. Singh, Substrate induced effects on structural, optical and electrical properties of lead (II)tetrakis (4-cumylphenoxy) phthalocyanine thin films, Materials Today: Proceedings 26 (2020) 3386-3389

[9] P. Zhu, P. Wang, W. Qiu, Y. Liu, C. Ye, Optical limiting properties of phthalocyanine-fullerene derivatives, Applied Physics Letters 78 (2001) 1319.

[10] S. Dogo, J.P. Germani, C. Maleysson, S. Pauly, Interaction of $\mathrm{NO}_{2}$ with copper phthalocyanine thin films I: Characterization of the copper phthalocyanine films, Thin Solid films 219 (1992) 244-250

[11] M.M. El-Nahass. H.S. Soliman, B.A. Khalifa, I.M. Soliman, Structural and optical properties of nanocrystalline aluminum phthalocyanine chloride thin films, Materials Science in Semiconductor Processing 38 (2015) 177-183

[12] E.F.M. El-Zaidi, Saleem I. Qashou, A.A.A. Darwish, I.S. Yahia, Thermally evaporated of homogeneous nanostructured gallium-phthalocyanine-chloride films: Optical spectroscopy, Optical Materials 109 (2020) 110407

[13] A.A.A. Darwish, Taymour A. Hamdalla, E.F.M. El-Zaidia, T.A. Hanafy, Shams A.M. Issa, I.S. Yahia, Thin films of nanostructured gallium (III) chloride phthalocyanine deposited on FTO: Structural characterization, optical properties, and laser optical limiting, Physica B 593 (2020) 412321 
[14] I.M. Soliman, M.M. El-Nahass, Y. Mansour, Electrical, dielectric and electrochemical measurements of bulk aluminum phthalocyanine chloride $(\mathrm{AlPcCl})$, Solid State Communications 225 (2016) 17-21

[15] K.R. Rajesh, C.S. Menon, Influence of oxygen and post-deposition annealing on the electrical properties of $\mathrm{MnPc}$ and $\mathrm{MnPcCl}$ Schottky barrier devices, Journal of Materials Science 40 (2005) $1115-1120$

[16] W.M. Darwish, A.M. Darwish, and E. Al-Ashkar, Synthesis and nonlinear optical properties of a novel indium phthalocyanine highly branched polymer. Polymers for Advanced Technologies, 2015. 26(8): p. 1014-1019.

[17] V. Chauke, A. Ogunsipe, M. Durmuş, T. Nyokong, Novel gallium(III) phthalocyanine derivatives - Synthesis, photophysics and photochemistry, Polyhedron 26 (2007) 2663-2671

[18] L.C. Zhang, L.Y. Chen, A review on biomedical titanium alloys: recent progress and prospect, Advanced Engineering Materials 21 (2019) 1801215.

[19] R.C. Cherian, C.S. Menon, Preparation and characterization of thermally evaporated titanium phthalocyanine dichloride thin films, Journal of Physics and Chemistry of Solids 69 (2008) $2858-2863$

[20] S. Tolansky, "Multiple-Beam Interference Microscopy of Metals", Academic Press, London, 1970, p. 55.

[21] M. Rashad, A.A.A. Darwish, A.A. Attia, Impact of film thickness on optical and electrical transport properties of noncrystalline $\mathrm{GeSe}_{1.4} \mathrm{Sn}_{0.6}$ films, Journal of Non-Crystalline Solids 470 (2017) 1-7

[22] M. Rashad, Taymour A. Hamdalla, S.E. Al Garni, A.A.A. Darwish, S.M. Seleim, Optical and electrical behaviors in $\mathrm{NiO} / \mathrm{xFe}_{2} \mathrm{O}_{3}$ nanoparticles synthesized by microwave irradiation method, Optical Materials 75 (2018) 869-874

[23] X. Zhang, W. Lin, H. Zhao, R. Wang, Raman spectra study of p-tert-butylphenoxy-substituted phthalocyanines with different central metal and substitution positions, Vibrational Spectroscopy 96 (2018) 26-31

[24] M. Ozta, Influence of Grain Size on Electrical and Optical Properties of InP Films, Chinese Physics Letters 25 (2008) 4090

[25] G. Reiss, H. Brückl, The influence of surface roughness on electronic transport in thin films, Surface Science 269-270 (1992) 772-776

[26] F. Ebrahimi, G.R. Bourne, M.S. Kelly, T.E. Matthews, Mechanical properties of nanocrystalline nickel produced by electrodeposition, Nanostructured Materials 11 (1999) 343350

[27] H. Munekata, H. Kukimoto, Electroluminescence in hydrogenated amorphous silicon-carbon alloy, Applied Physics Letters 42 (1983) 432.

[28] I.S. Yahia, H.Y. Zahran, F.H. Alamri, Spectrophotometric calculations of optical linearity and nonlinearity of nanostructured Pyronin Y/FTO optical system for optoelectronic applications, Synthetic Metals 222 (2016) 186-191 
[29] H.M. Zeyad, M.M. El-Nahass, I.K. El-Zawawi, E.M. El-Menyawy, Structural and optical properties of thermally evaporated-2,3)-2dihydro-1,5-dimethyl-3-oxo-2-phenyl-1H-pyrazol-4ylimino-4)-2 -(nitrophenyl)acetonitrile thin films, Journal of Physics and Chemistry of Solids 71 (2010) 867-873

[30] M.M. El-Nahass, K.F. Abd El Rahman, A.A.M. Farag, A.A.A. Darwish, Optical characterization of thermally evaporated nickel phthalocyanine thin films, International Journal of Modern Physics B 18 (2004) 421-434

[31] M.M. El-Nahass, H.M. Abd El-Khalek, A.M. Nawar, Structural and optical characterizations of Ni (II) tetraphenyl porphyrin thin films, The European Physical Journal - Applied Physics 57 (2012) 30201

[32] Taymour A. Hamdalla, Seleim M. Seleim, Rabah Hanem, A. Mohamed, A.A.A. Darwish, T.A. Hanafy, Mohamed E. Mahmoud, Synthesis, characterization and optical properties of nanosized lanthanum (III) complexes thin film with aryl-azo-pyrogallol derivatives, Spectrochimica Acta Part A: Molecular and Biomolecular 238 (2020) 118448

[33] S. Zahedi \& D. Dorranian, Effect of laser treatment on the optical properties of poly(methyl methacrylate) thin films, Optical Review 20 (2013) 36-40

[34] Y. Khairy, M.I. Mohammed, H.I. Elsaeedy, I.S. Yahia, Synthesis, optical limiting and properties of Rhodamine B-doped PMMA polymeric films/glass substrate: New trends in polymeric composites, Optik 212 (2020)164687

[35] T.F. Zhang, X.G. Tang, Q.X. Liu, Y.P. Jiang, L.L. Jiang, L. Luo, Optical and dielectric properties of $\mathrm{PbZrO} 3$ thin films prepared by a sol-gel process for energy-storage application, Materials and Design 90 (2016) 410-415

[36] J. Mistrik, S. Kasap, H.E. Ruda, C. Koughia, J. Singh, (2017), Optical Properties of Electronic Materials: Fundamentals and Characterization. In: Kasap S., Capper P. (eds) Springer Handbook of Electronic and Photonic Materials. Springer Handbooks. Springer, Cham. https://doi.org/10.1007/978-3-319-48933-9_3

[37] M.M. El-Nahass, A.M. Farag, K.F. Abd El-Rahman, A.A.A. Darwish, Dispersion studies and electronic transitions in nickel phthalocyanine thin films, Optics \& Laser Technology 37 (2005) 513-523

[38] J. Bardeen, F.J. Blatt, L.H. Hall, Proceedings of the Conference on Photoconductivity, Atlantic City 4-6 (1965) 149

[39] A.A.A. Darwish, Saleem I. Qashou, Z. Khattari, Mustafa M. Hawamdeh, Allayth Aldrabee, S.E. Al Garni, Effect of gamma radiation induced on structural, electrical, and optical properties of N, N'-Dimethyl-3,4,9,10 perylenedicarboximide nanostructure films, Journal of Electronic Materials 47 (2018) 7196-7203

[40] M.M. El-Nahass, K.F. Abd-El-Rahman, A.A. Al-Ghamdi, A.M. Asiri, Optical properties of thermally evaporated tin-phthalocyanine dichloride thin films, SnPcCl2, Physica B 344 (2004) $398-406$ 
[41] S.H. Wemple, M.D. DiDomenico, Behavior of the electronic dielectric constant in covalent and ionic materials, Phys. Rev. B 3 (1970) 1338

[42] Sherif S. Nafee, Taymour A. Hamdalla, A.A.A. Darwish, Studies of the morphology and optical properties of nano erbium oxide embedded in PMMA matrix, Optics \& Laser Technology 129 (2020) 106282.

[43] E.F.M. El-Zaidia, M.S. Al-Kotb, I.S. Yahia, Deposition of nanostructured methyl violet-10B films/FTO: optical limiting and optical linearity/nonlinearity, Materials Chemistry and Physics 240 (2020) 122074

[44] Q.M. Ali, P.K. Palanisamy, Investigation of nonlinear optical properties of organic dye by Zscan technique using He-Ne laser, Optik, 116 (2005) 515-520

[45] D. Arivuoli, Fundamentals of nonlinear optical materials, Pramana - J. Phys. 57 (2001) 871883

[46] L. Tichý, H. Ticha, P. Nagels, R. Callaerts, R. Mertens, M. Vlcek, optical properties of amorphous As-Se and Ge-As-Se thin films, Mater. Lett., 39 (1999) 122-128.

[47] G.I. Stegeman, E.M. Wright, N. Finlayson, R. Zanoni, C.T. Seaton, Third-order nonlinear integrated optics, Journal of lightwave technology 6 (1988) 953-970 


\section{Figures}

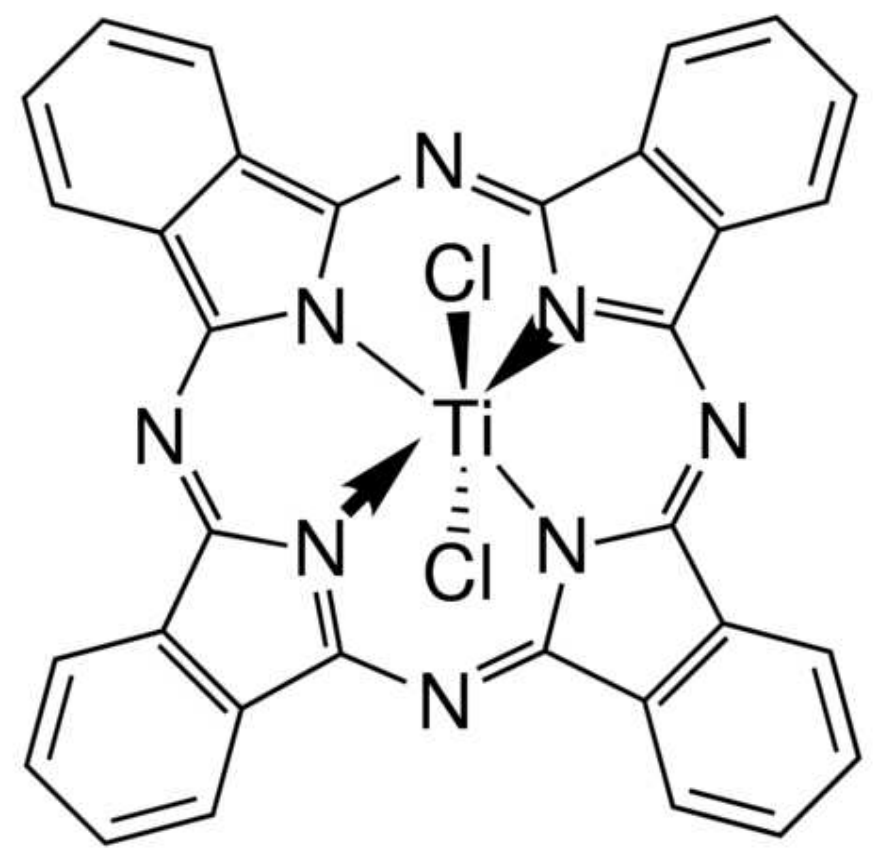

Scheme 1:The molecular structure of $\mathrm{TiPcCl}_{2}$ compounds 


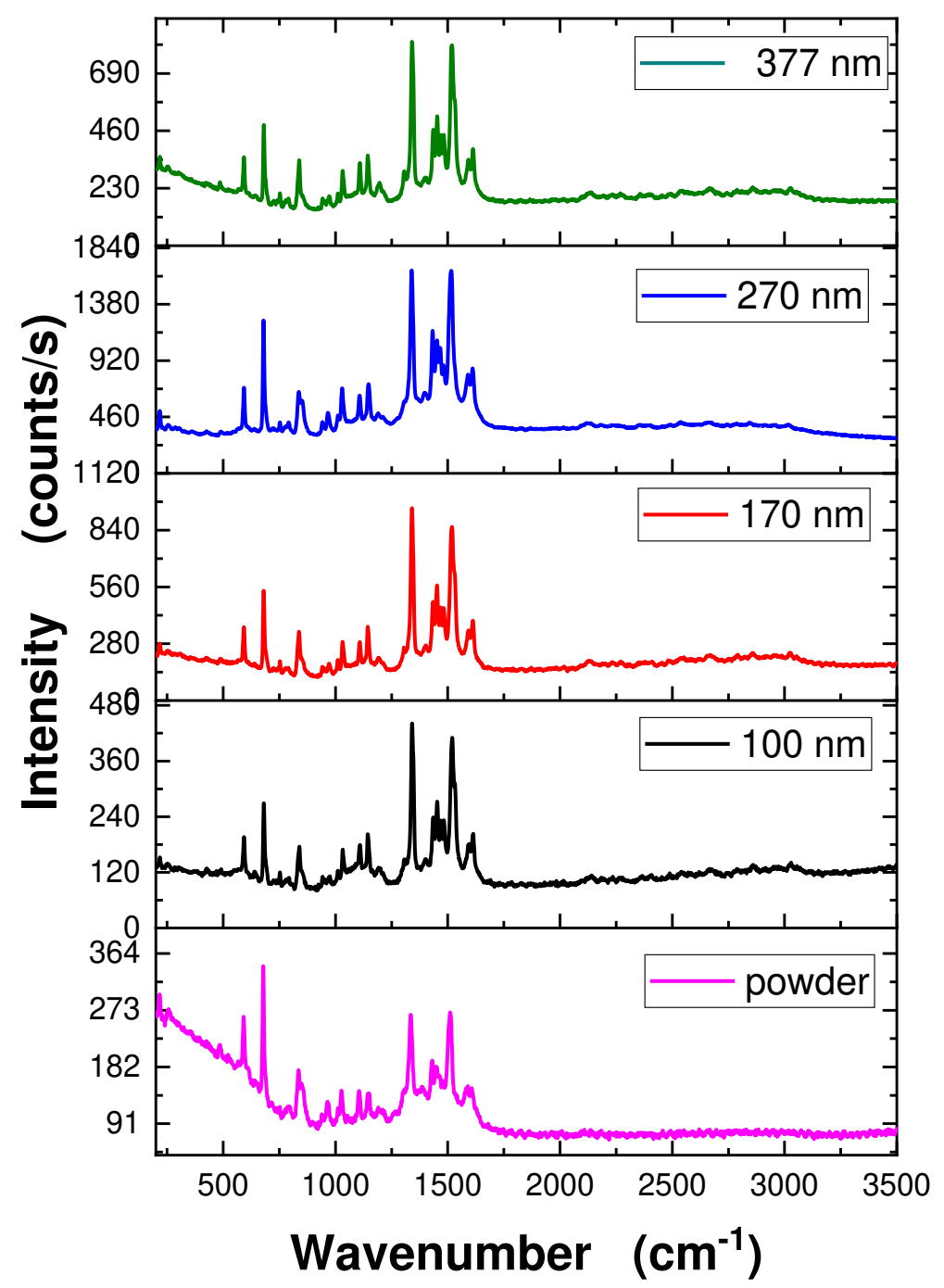

Fig. 1: Raman spectroscopy of powder and $\mathrm{TiPcCl}_{2}$ film with different thickness 


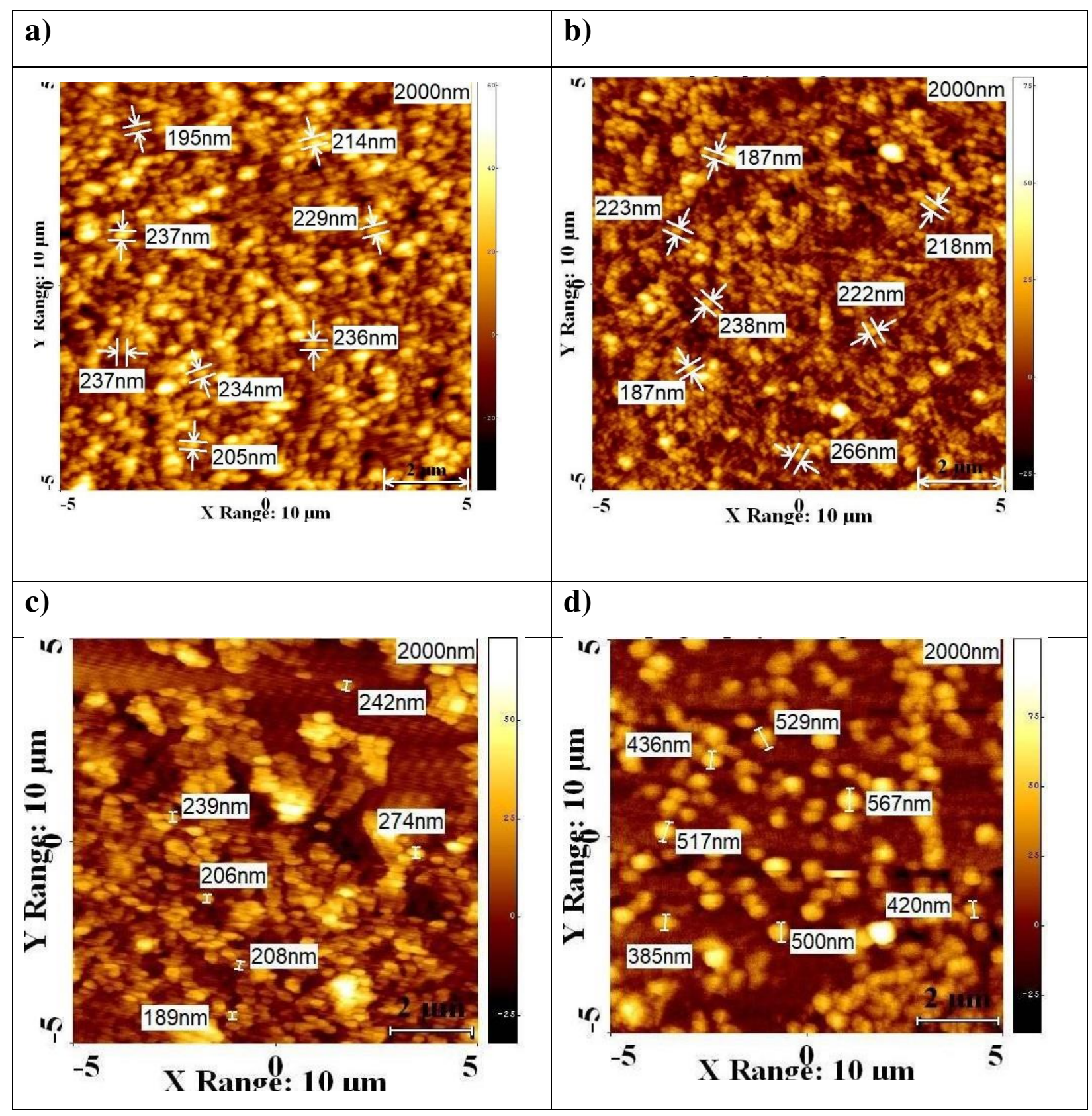

Fig. 2: $2 \mathrm{D}$ AFM images of $\mathrm{TiPcCl}_{2}$ film with different thickness (a) $100 \mathrm{~nm}$ (b) $170 \mathrm{~nm}$ (c) 270 $\mathrm{nm}$ and (d) $377 \mathrm{~nm}$ 


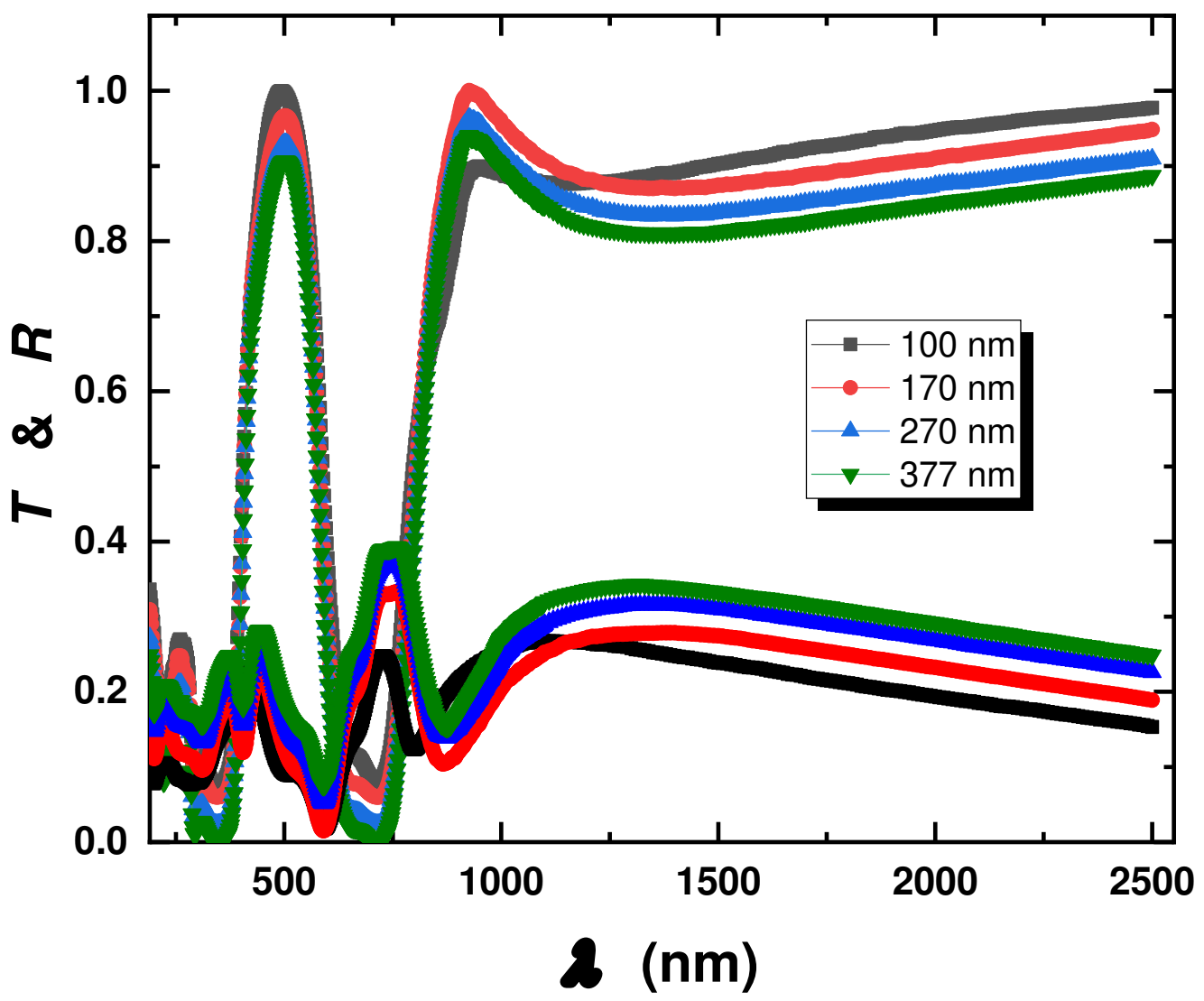

Fig. 3: Spectra of $T$ and $R$ of $\mathrm{TiPcCl}_{2}$ films with different thicknesses 

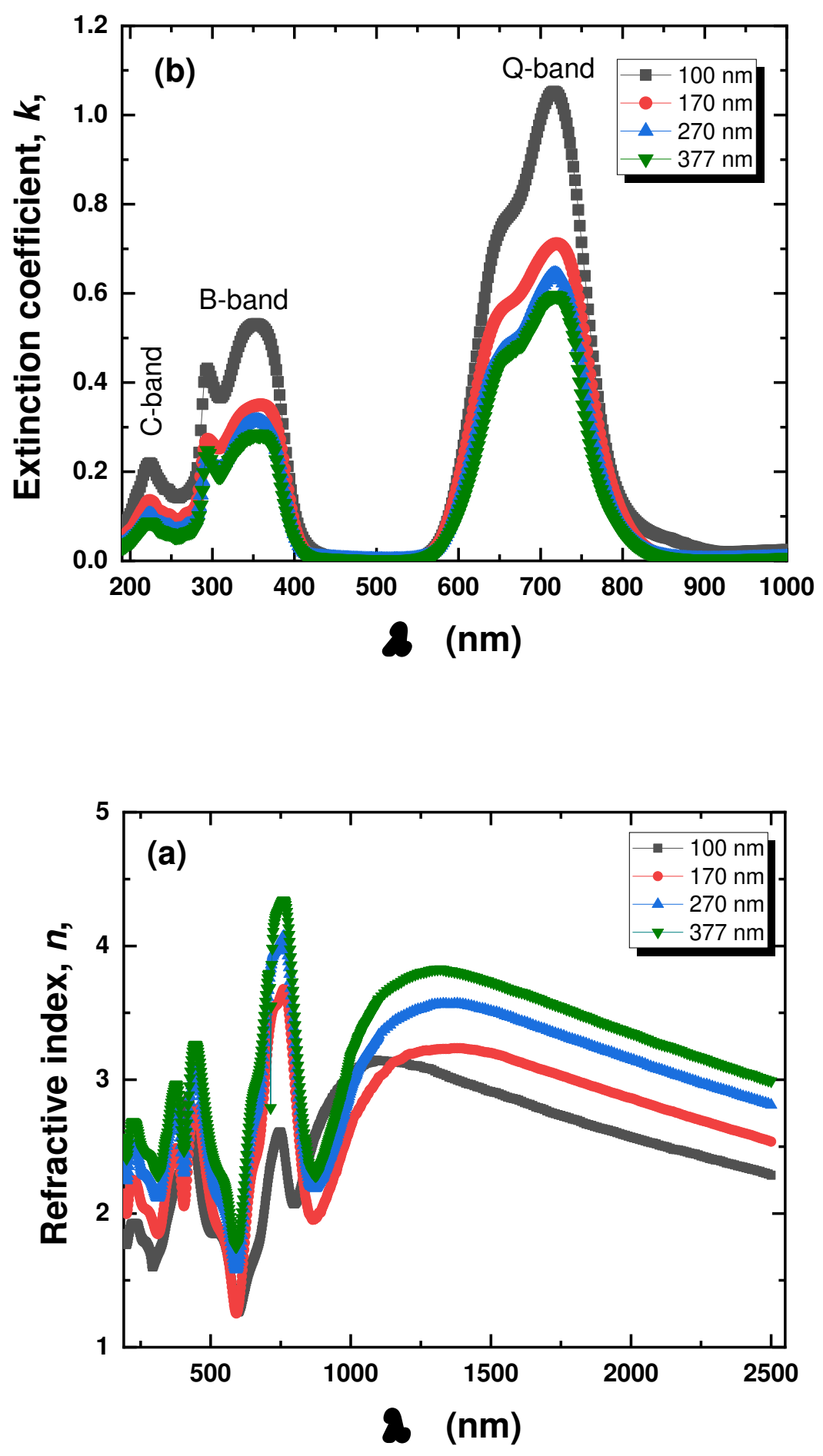

Fig. 4: Spectra of (a) the refractive index, $n$, and (b) extinction coefficient, $k$, of $\mathrm{TiPcCl}_{2}$ films with different thicknesses. 

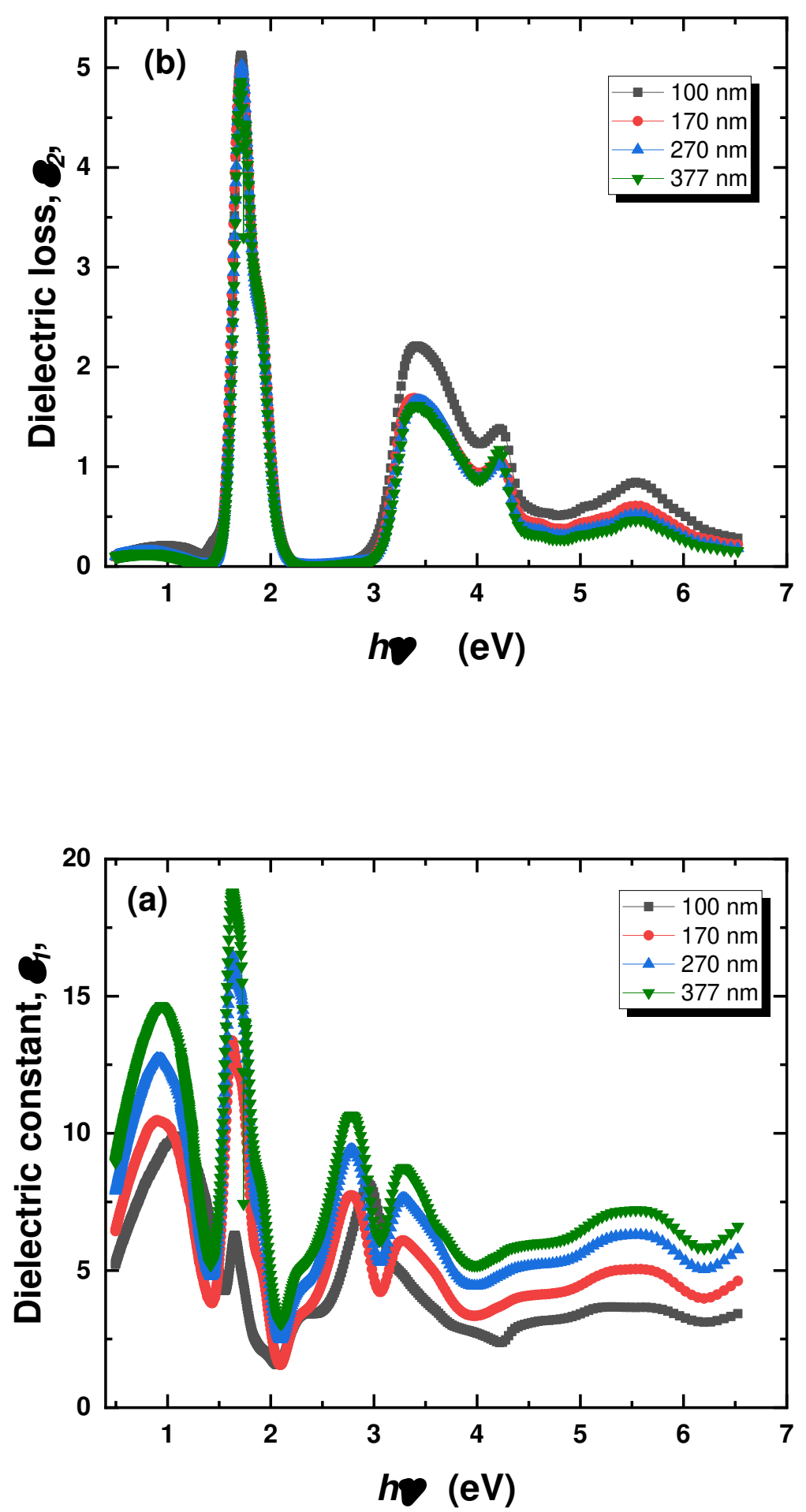

Fig. 5: Spectra of (a) the dielectric constant, $\varepsilon_{1}$, and (b) dielectric loss, $\varepsilon_{2}$, of $\mathrm{TiPcCl}_{2}$ films with different thicknesses. 


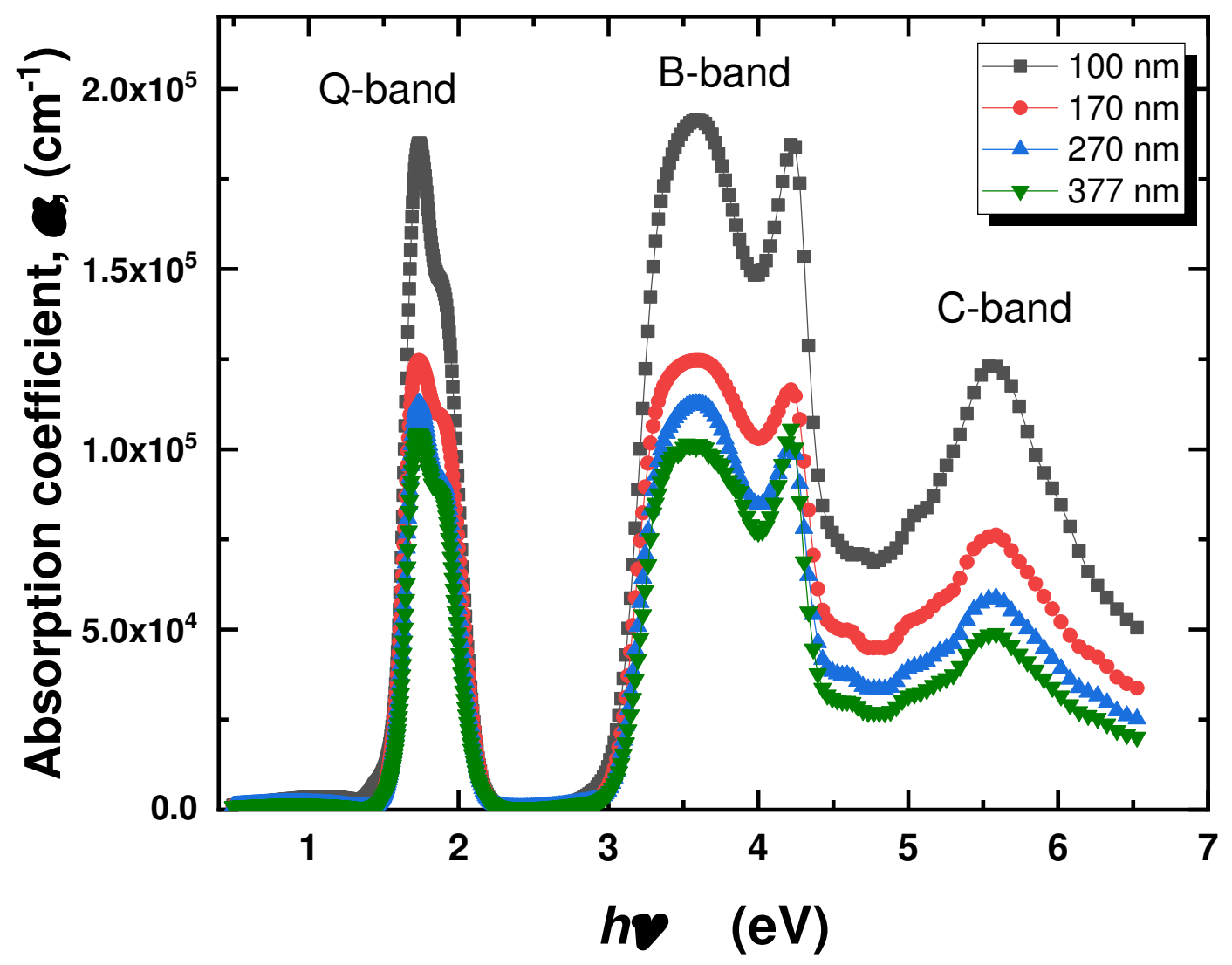

Fig. 6: Spectra of the absorption coefficient, $\alpha$, of $\mathrm{TiPcCl}_{2}$ films with different thicknesses. 

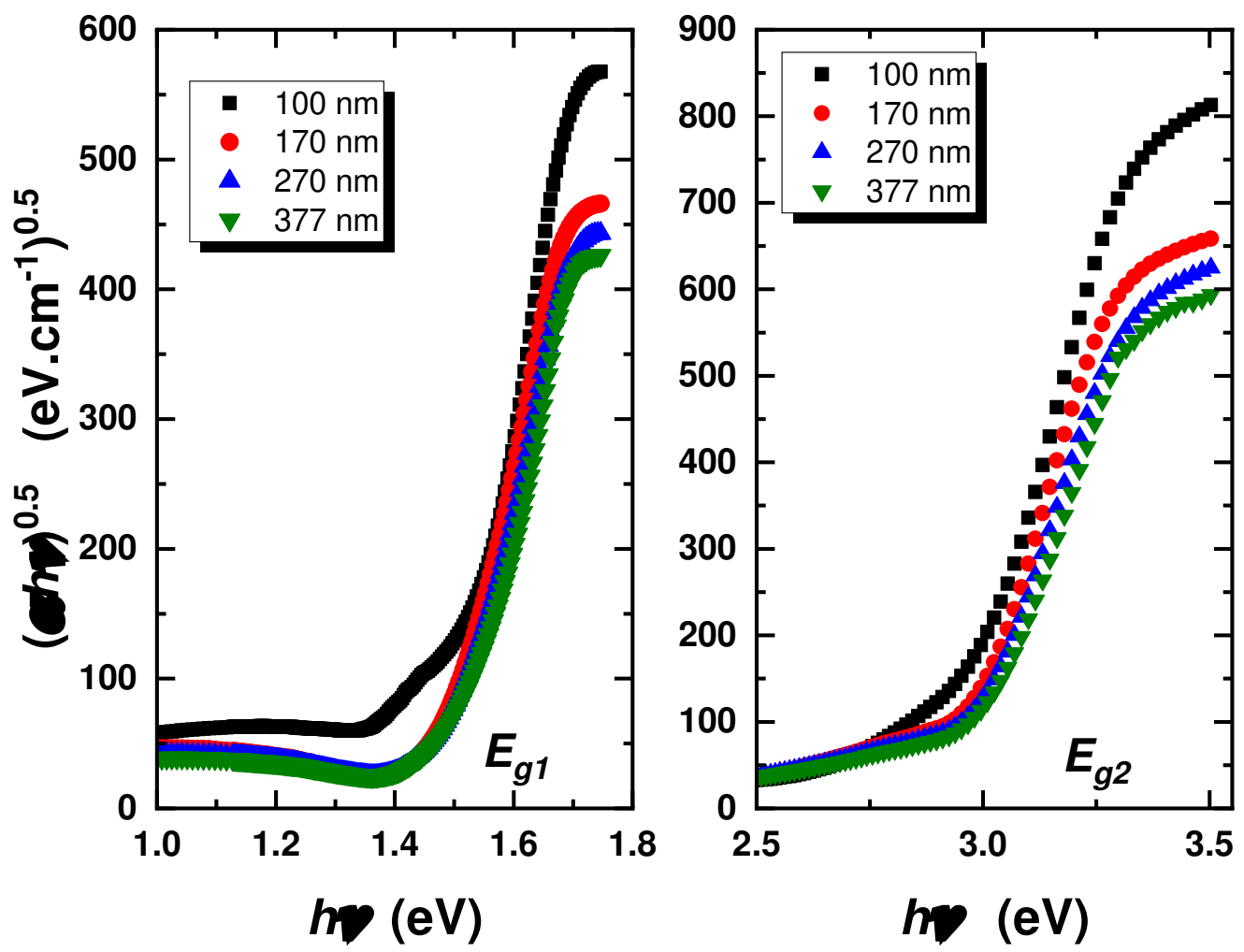

Fig. 7: The relation between $(\alpha h v)^{0.5}$ and $h v$ for $\mathrm{TiPcCl}_{2}$ films with different thicknesses 

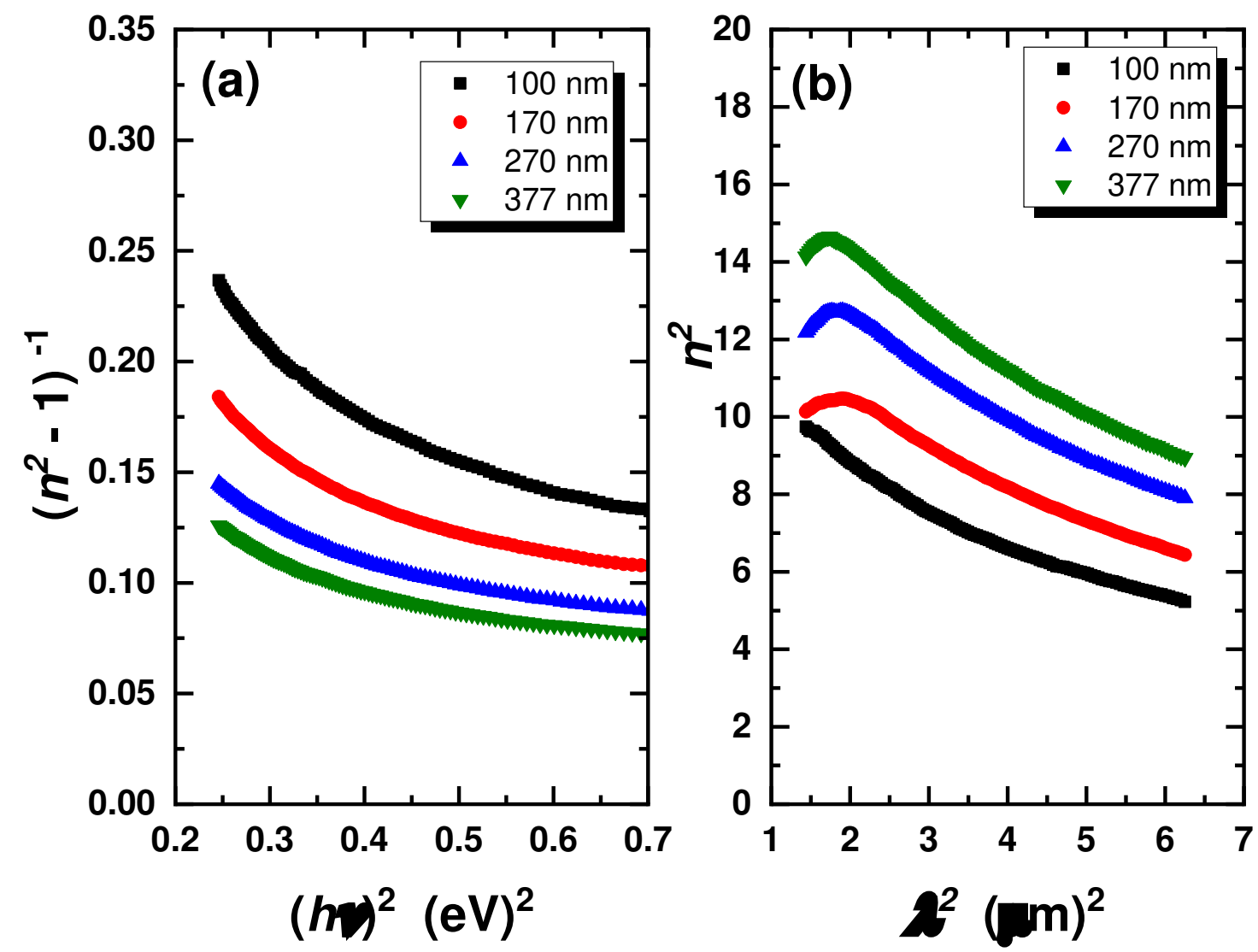

Fig. 8: a) the relation between $\left(n^{2}-1\right)^{-1}$ and $(h \gamma)^{2}$, b) the relation between $n^{2}$ and $\lambda^{2}$ for $\mathrm{TiPcCl}_{2}$ films 


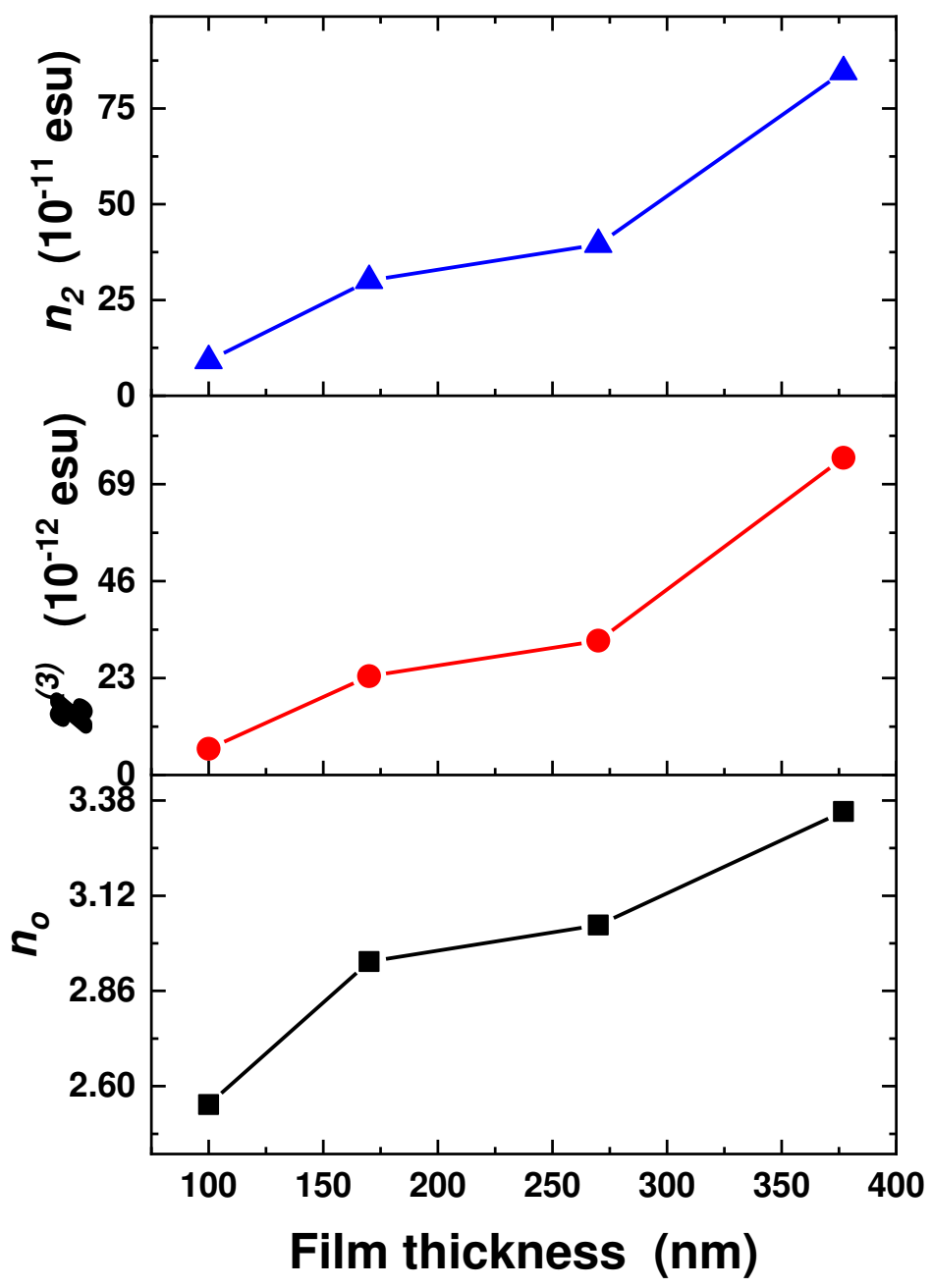

Fig. 9: The nonlinear optical parameters of $\mathrm{TiPcCl}_{2}$ films as a function of film thickness 


\section{Tables}

Table 1: Raman peaks of the $\mathrm{TiPcCl}_{2}$ powder and its films

\begin{tabular}{|c|c|c|c|c|}
\hline \multirow{2}{*}{ No } & \multicolumn{3}{|c|}{ Wavenumber $\left(\mathrm{cm}^{-1}\right)$} & \multirow{2}{*}{ Bonds } \\
\hline & Powder & Films (100 nm) & Films (377 nm) & \\
\hline 1 & 593 & 592 & 592 & $* * * * * * * * * * * * * * * * * * * * * * * * *$ \\
\hline 2 & 677 & 681 & 681 & $\mathrm{C}-\mathrm{O}$ \\
\hline 3 & 832 & 838 & 839 & $* * * * * * * * * * * * * * * * * *$ \\
\hline 4 & 967 & 964 & 970 & $* * * * * * * * * * * * * * * * * * * * *$ \\
\hline 5 & 1030 & 1032 & 1033 & $* * * * * * * * * * * * * *$ \\
\hline 6 & 1105 & 1110 & 1108 & $\mathrm{C}-\mathrm{C}$ \\
\hline 7 & 1150 & 1144 & 1143 & $* * * * * * * * * * * * * * * * * * * * * * * * * * *$ \\
\hline 8 & 1336 & 1340 & 1340 & $\mathrm{C}-\mathrm{O}$ \\
\hline 9 & 1430 & 1432 & 1451 & $\mathrm{C}-\mathrm{H}$ \\
\hline 10 & 1514 & 1517 & 1519 & $\mathrm{C}=\mathrm{C}$ \\
\hline 11 & 1589 & 1613 & 1612 & $\mathrm{C}=\mathrm{C}$ \\
\hline
\end{tabular}

Table 2: Surface and linear optical parameters of $\mathrm{TiPcCl}_{2}$ films

\begin{tabular}{|c|c|c|c|c|c|c|c|c|c|c|}
\hline Film & $\begin{array}{l}\text { Grain } \\
\text { size } \\
(\mathbf{n m})\end{array}$ & $\begin{array}{l}\text { Roughness } \\
(\mathbf{n m})\end{array}$ & $\begin{array}{l}E_{g 1} \\
(\mathrm{eV})\end{array}$ & $\begin{array}{l}E_{g 2} \\
(\mathrm{eV})\end{array}$ & $\begin{array}{l}E_{o} \\
(\mathrm{eV})\end{array}$ & $\begin{array}{l}E_{d} \\
(\mathrm{eV})\end{array}$ & $\varepsilon_{\infty}$ & $\varepsilon_{L}$ & $\begin{array}{l}N / m^{*} \\
\left(\times 10^{46} \mathrm{~g}^{-}\right. \\
\left.{ }^{1} \mathrm{~cm}^{-3}\right)\end{array}$ & Ref \\
\hline $\mathrm{TiPcCl}_{2}(100 \mathrm{~nm})$ & 223 & 41.0 & 1.50 & 2.93 & 1.21 & 8.85 & 6.49 & 9.35 & 5.45 & $\begin{array}{l}\text { Current } \\
\text { work }\end{array}$ \\
\hline $\mathrm{TiPcCl}_{2}(170 \mathrm{~nm})$ & 233 & 42.0 & 1.49 & 2.94 & 1.33 & 15.60 & 8.66 & 11.75 & 7.17 & $\begin{array}{l}\text { Current } \\
\text { work }\end{array}$ \\
\hline $\mathrm{TiPcCl}_{2}(270 \mathrm{~nm})$ & 240 & 53.8 & 1.49 & 2.94 & 1.21 & 13.25 & 9.27 & 13.57 & 7.48 & $\begin{array}{l}\text { Current } \\
\text { work }\end{array}$ \\
\hline $\mathrm{TiPcCl}_{2}(377 \mathrm{~nm})$ & 479 & 57.9 & 1.51 & 2.96 & 1.28 & 18.83 & 11.25 & 15.52 & 8.73 & $\begin{array}{l}\text { Current } \\
\text { work }\end{array}$ \\
\hline $\mathrm{AlPcCl}$ & --- & --- & 1.42 & 2.87 & 1.59 & 4.04 & 3.53 & 4.86 & 8.9 & {$[11]$} \\
\hline $\mathrm{GaClPc}$ & 125.5 & 82.9 & 1.49 & 2.92 & 1.09 & 5.62 & 5.46 & 9.87 & 10.3 & [12] \\
\hline $\mathrm{SnPcCl}_{2}$ & --- & --- & 1.51 & 2.97 & --- & --- & -- & --- & -- & {$[40]$} \\
\hline
\end{tabular}


Figures

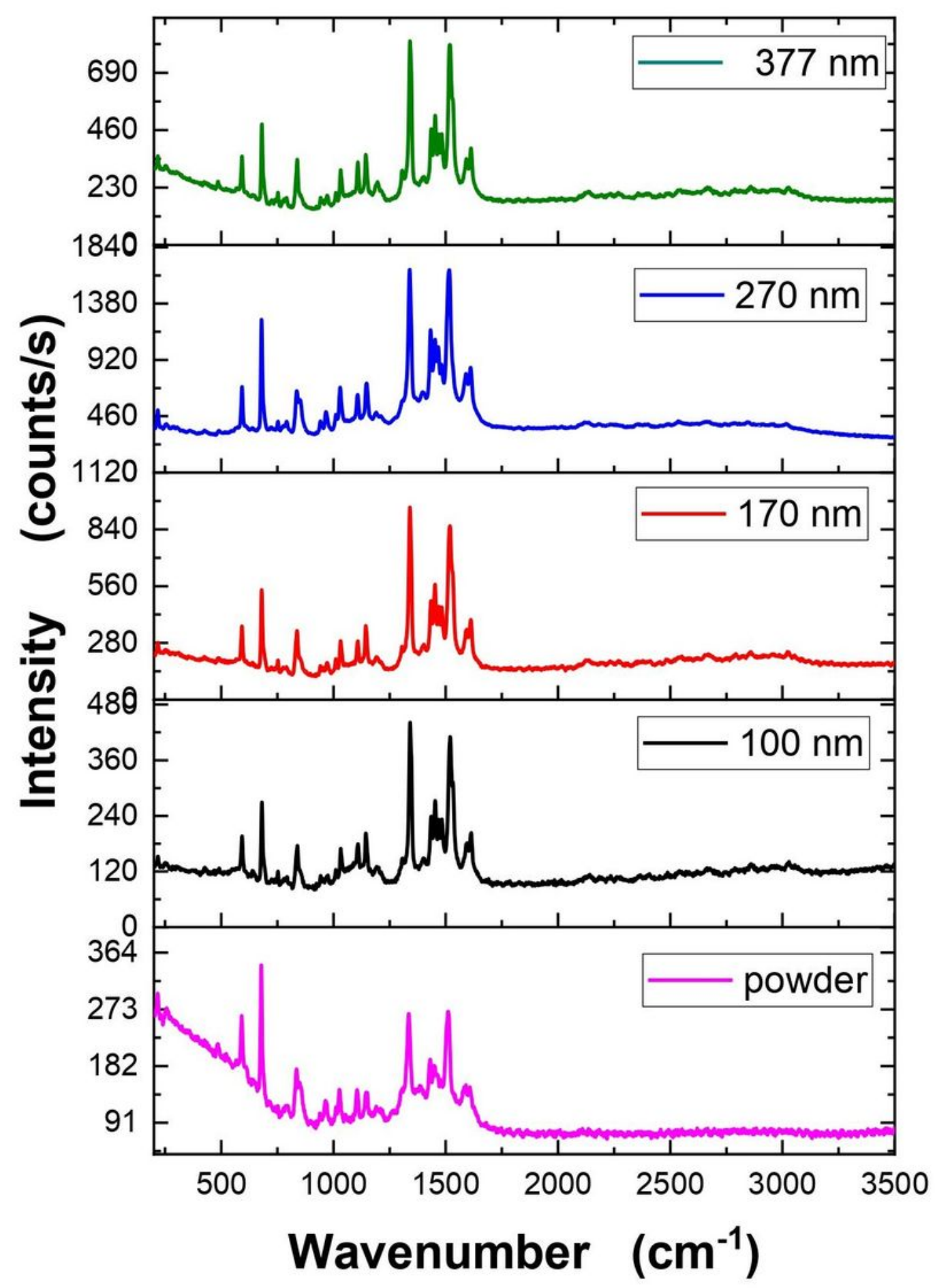

Figure 1

Raman spectroscopy of powder and $\mathrm{TiPcCl} 2$ film with different thickness 


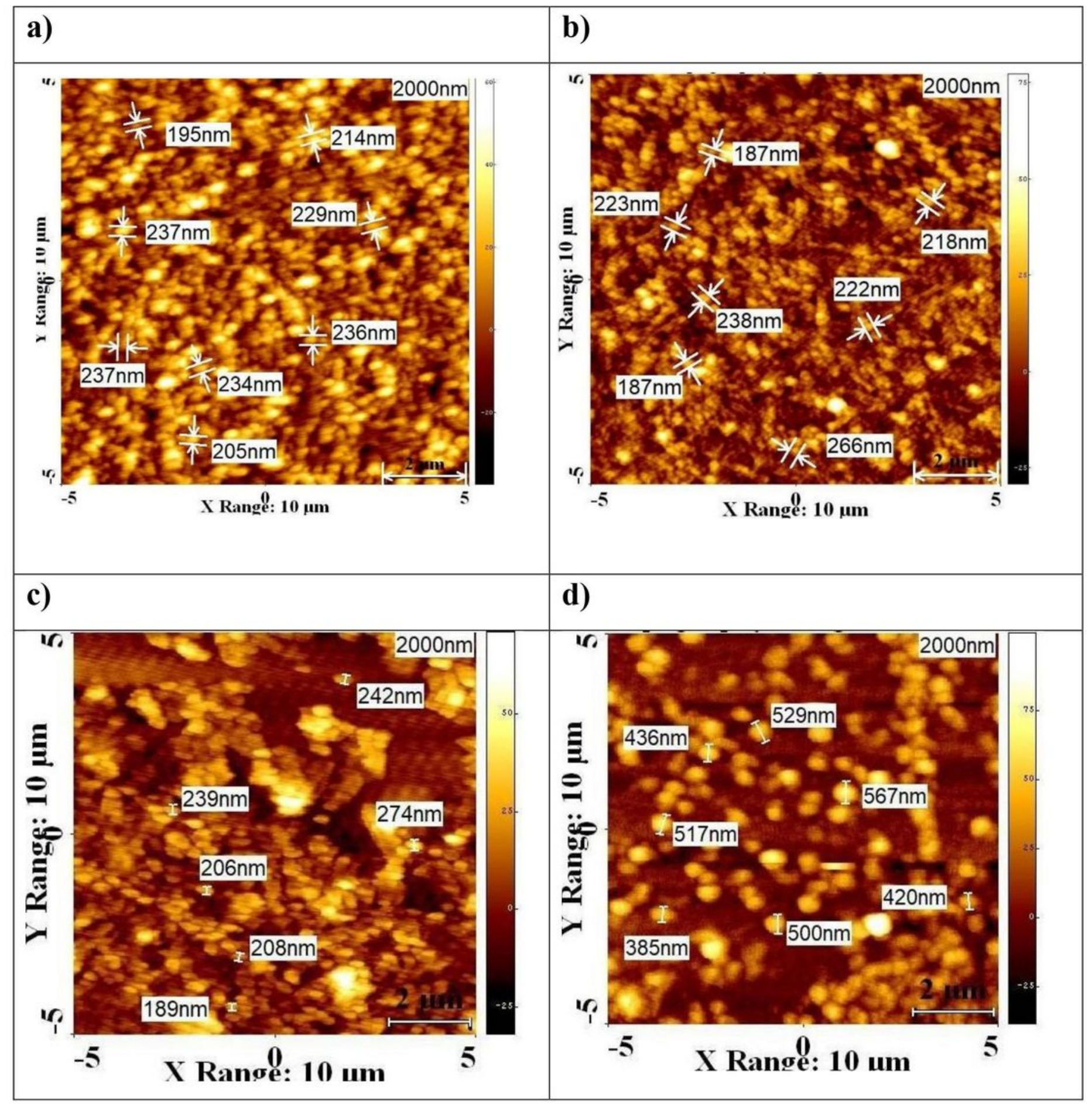

Figure 2

2D AFM images of TiPcCl2 film with different thickness (a) $100 \mathrm{~nm}$ (b) $170 \mathrm{~nm}$ (c) $270 \mathrm{~nm}$ and (d) 377 $\mathrm{nm}$ 


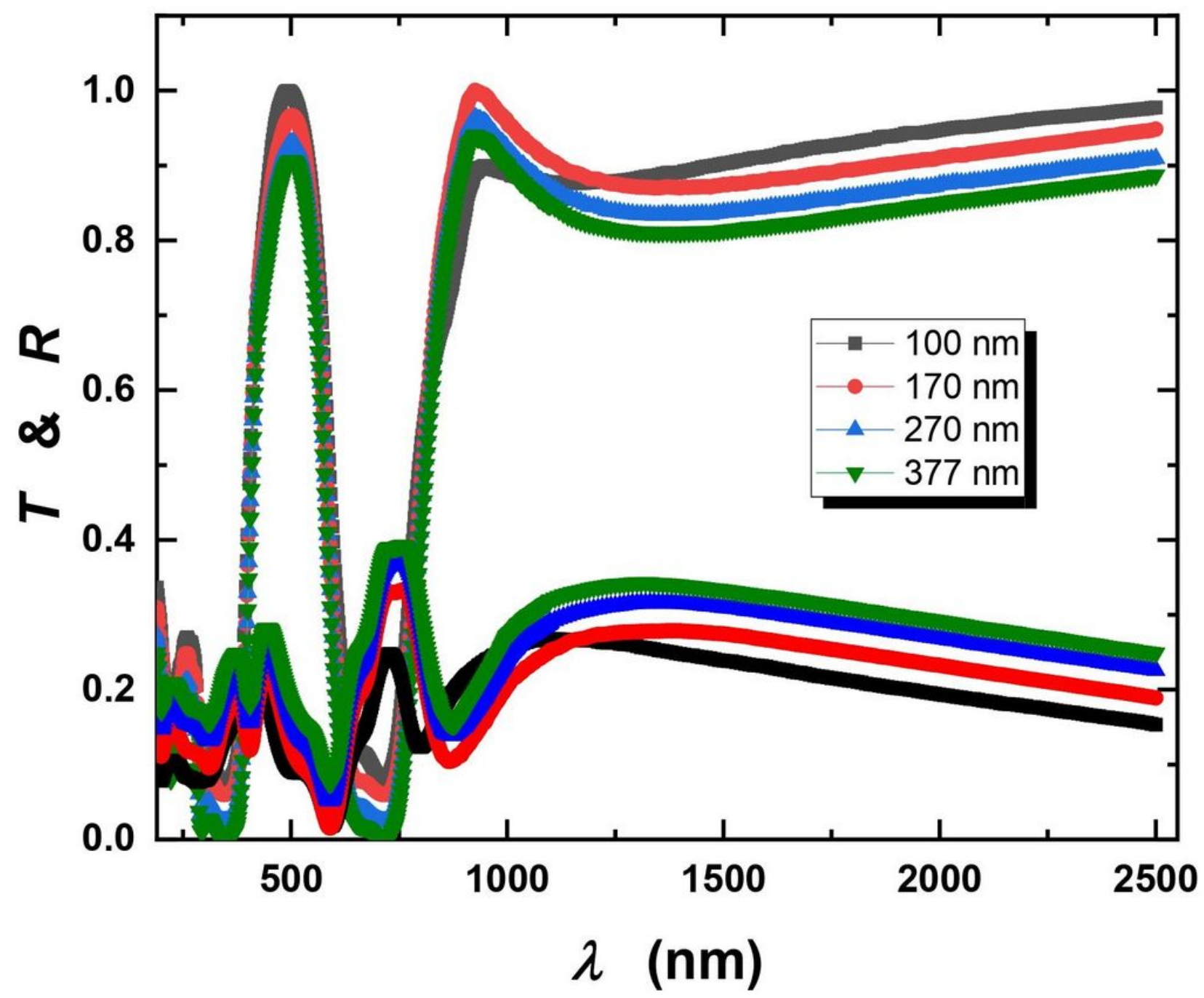

Figure 3

Spectra of $\mathrm{T}$ and $\mathrm{R}$ of $\mathrm{TiPcCl} 2$ films with different thicknesses 

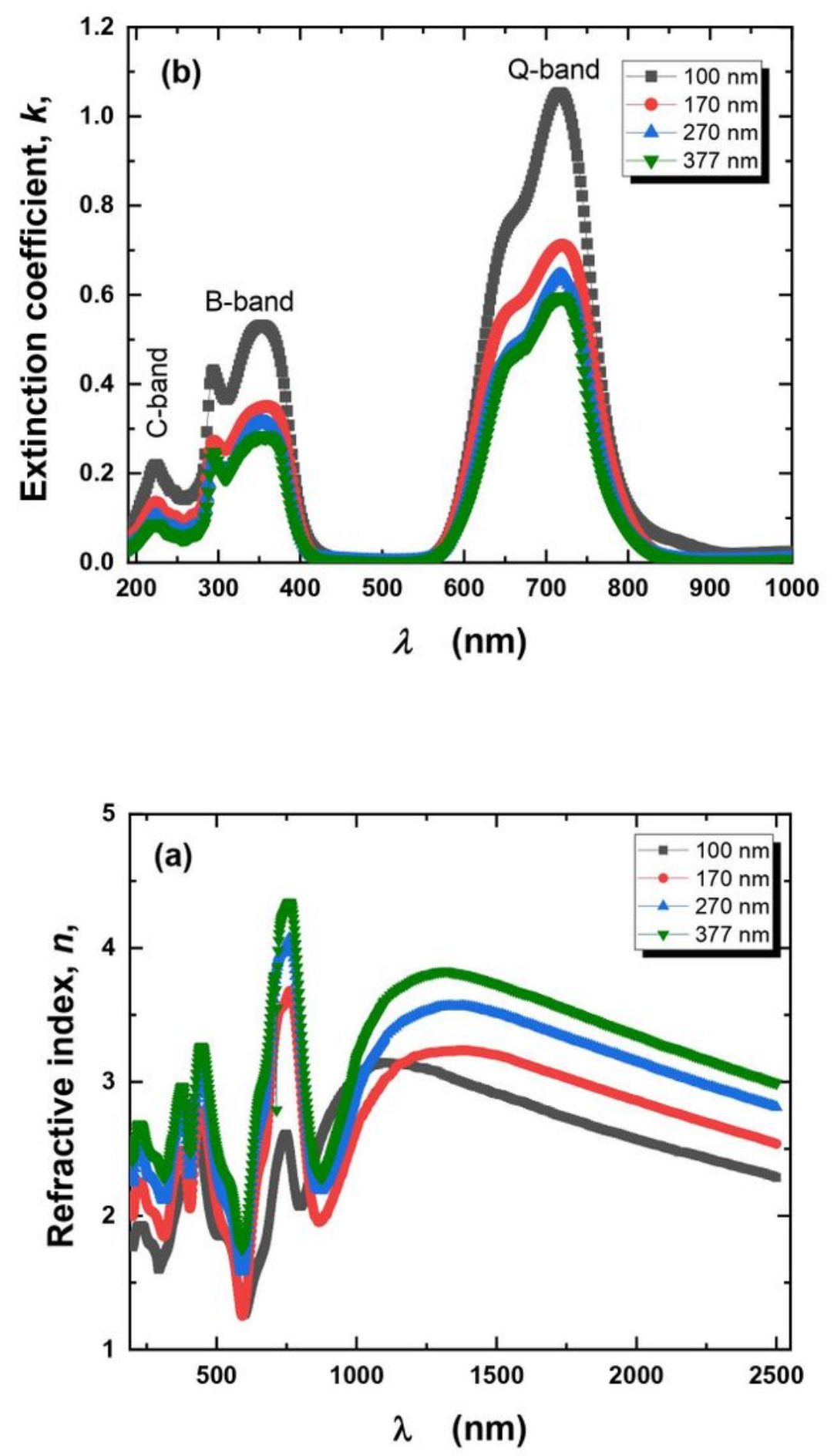

Figure 4

Spectra of (a) the refractive index, n, and (b) extinction coefficient, $k$, of TiPcCl2 films with different thicknesses. 

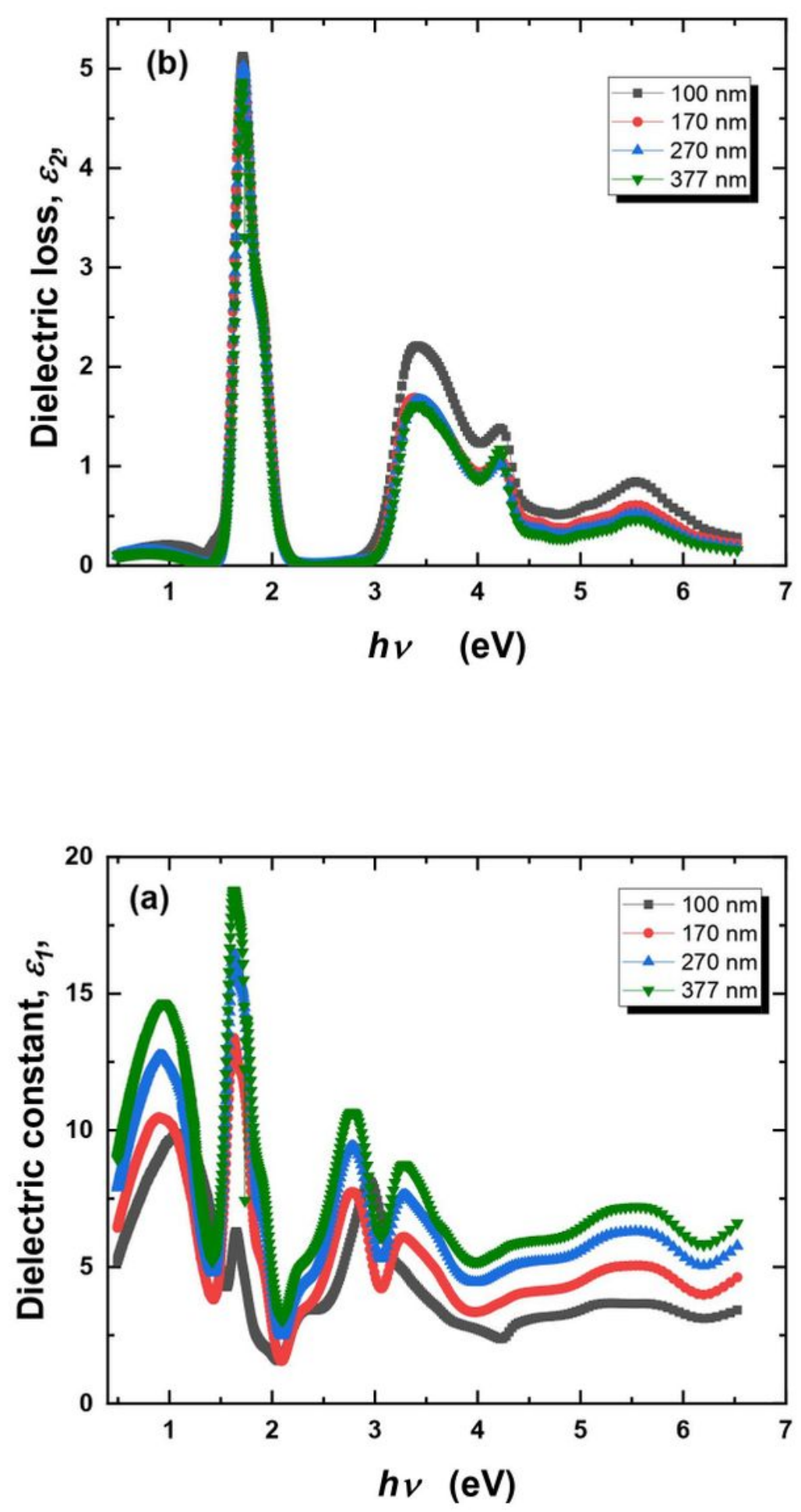

Figure 5

Spectra of (a) the dielectric constant, $\varepsilon 1$, and (b) dielectric loss, $\varepsilon 2$, of TiPcCl2 films with different thicknesses. 


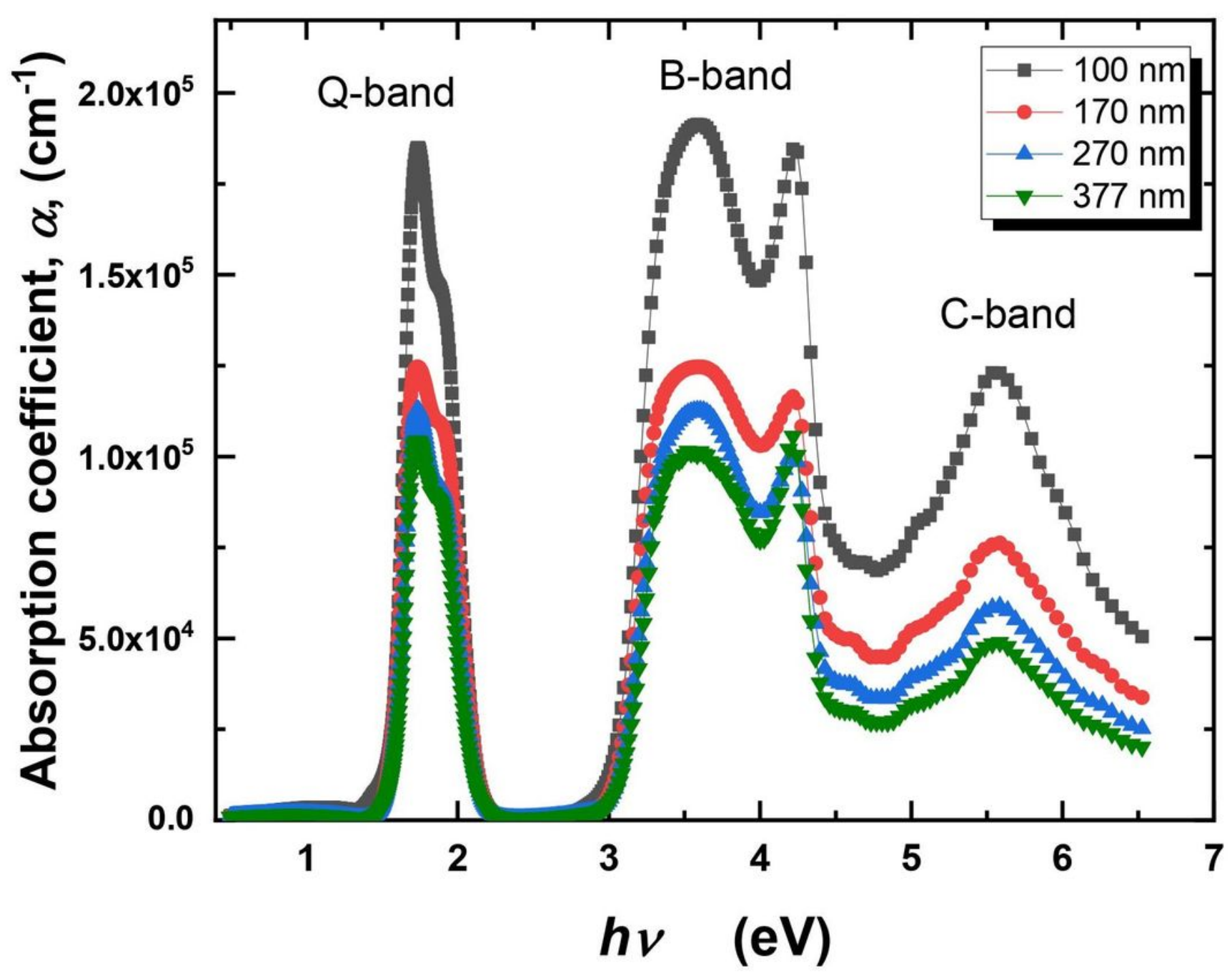

Figure 6

Spectra of the absorption coefficient, a, of TiPcCl2 films with different thicknesses. 

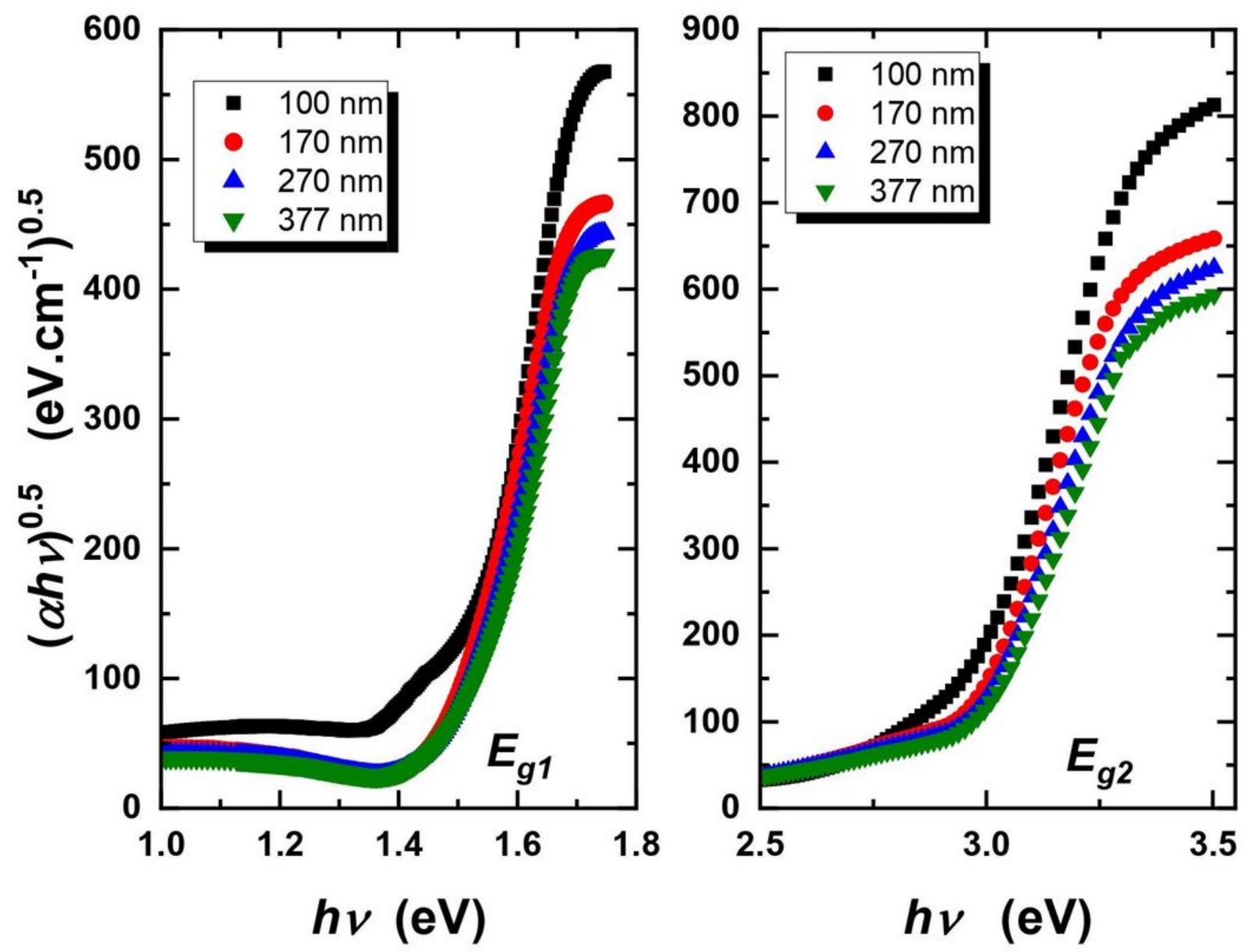

Figure 7

The relation between (ahv) 0.5 and hv for TiPcCl2 films with different thicknesses 

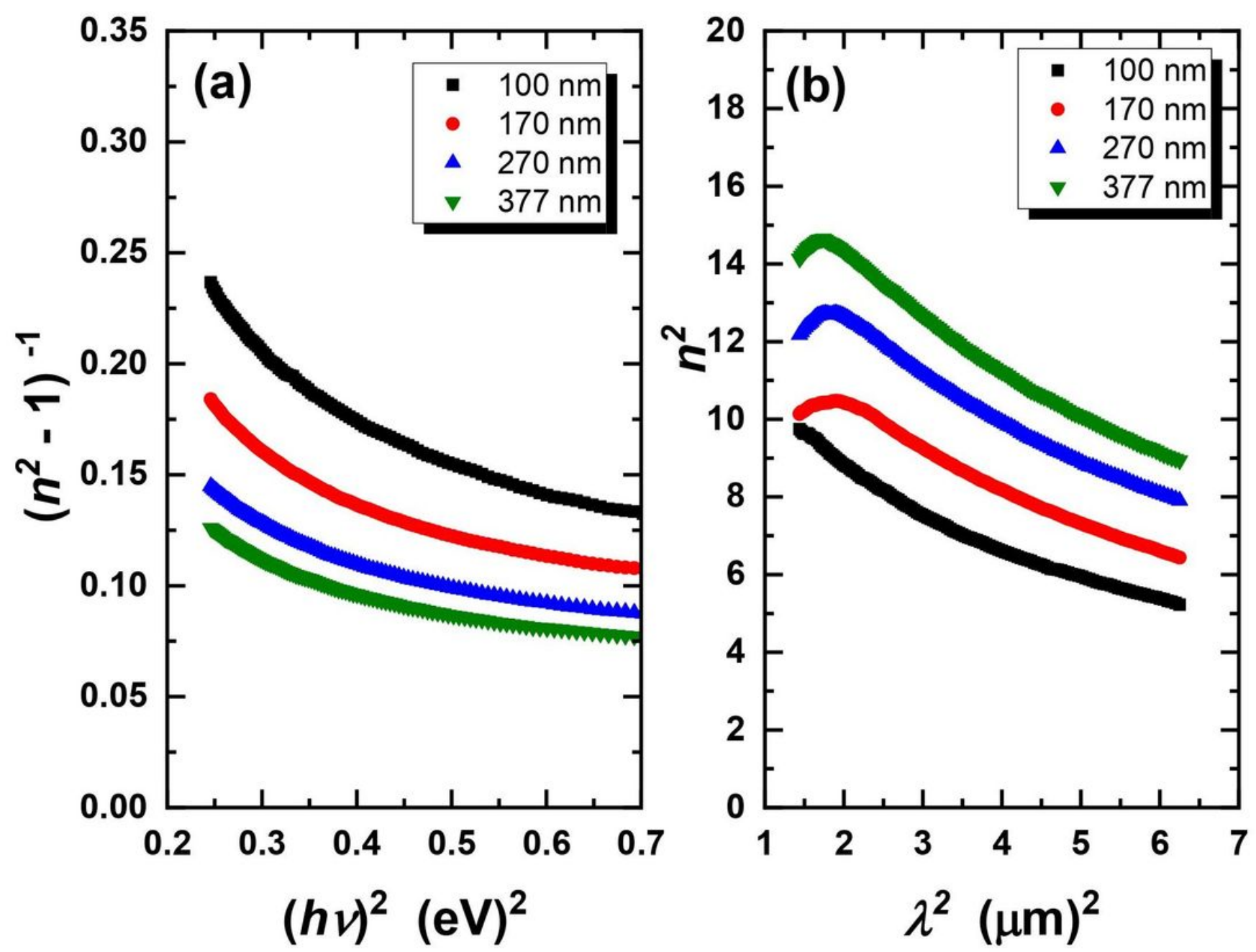

Figure 8

a) the relation between (n2-1)-1 and ( $\mathrm{h} \rrbracket) 2, \mathrm{~b})$ the relation between $\mathrm{n} 2$ and $\lambda 2$ for TiPcCl2 films 


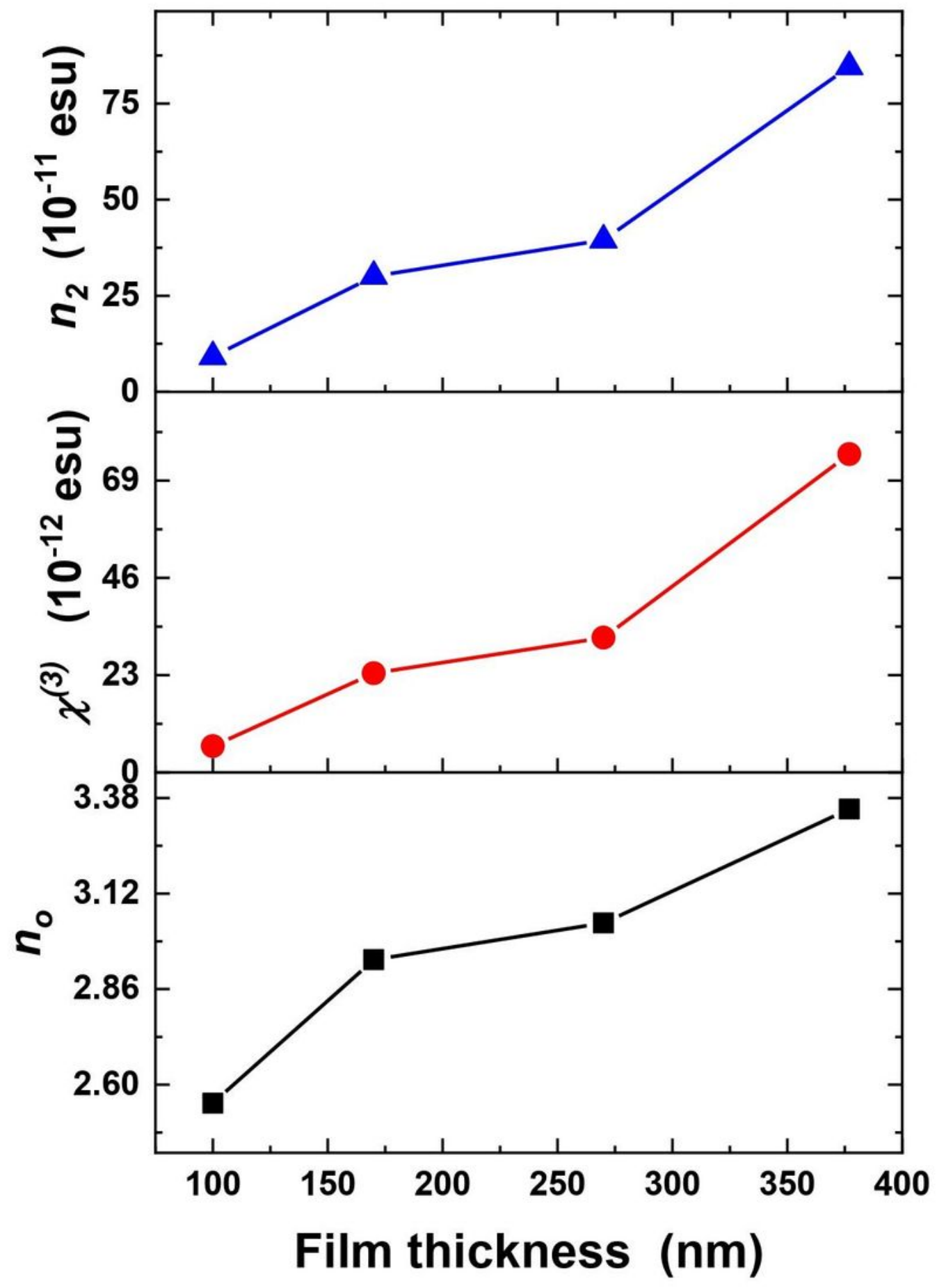

Figure 9

The nonlinear optical parameters of $\mathrm{TiPcCl} 2$ films as a function of film thickness 


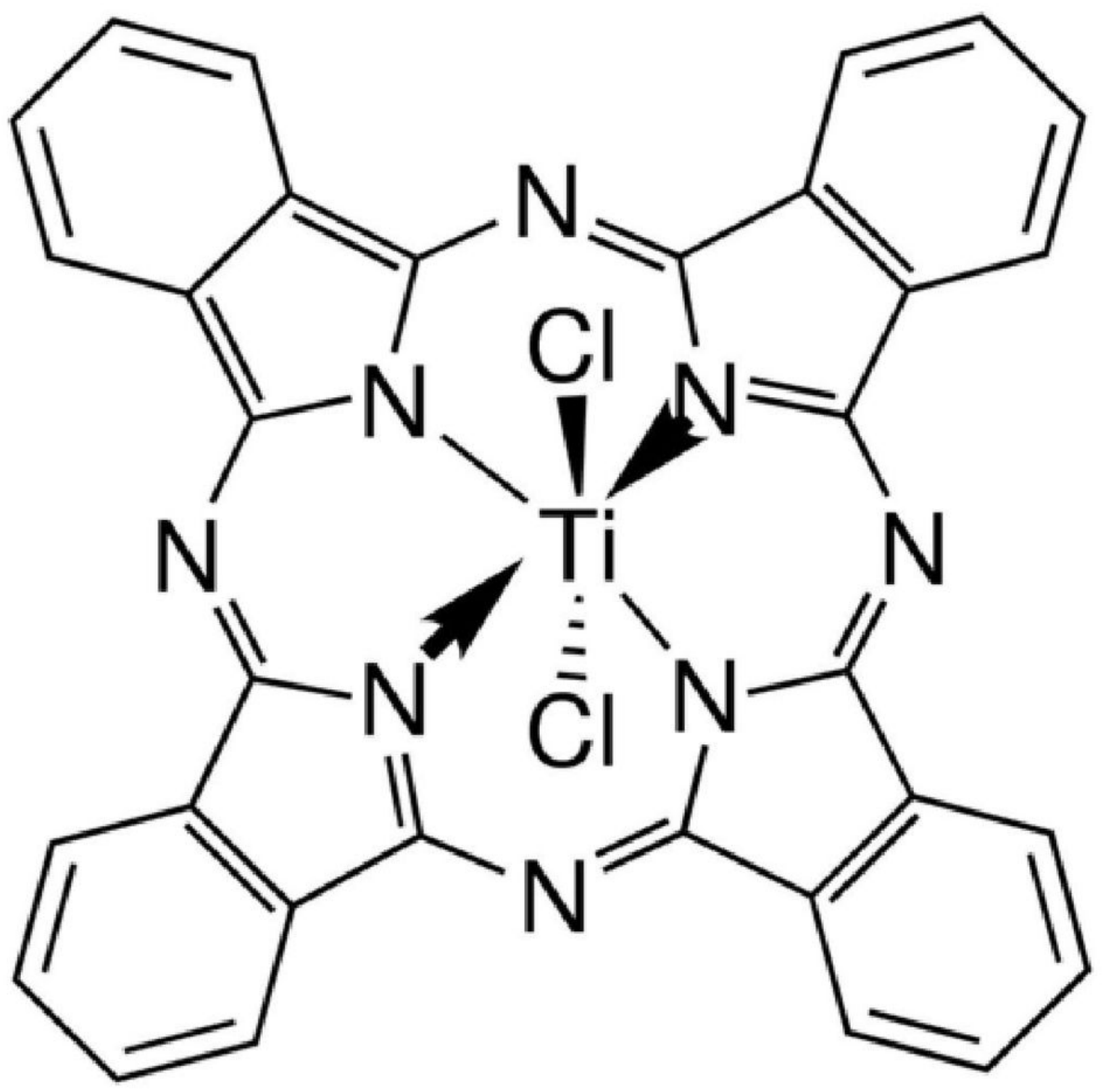

Figure 10

Scheme1-The molecular structure of $\mathrm{TiPcCl} 2$ compounds 